
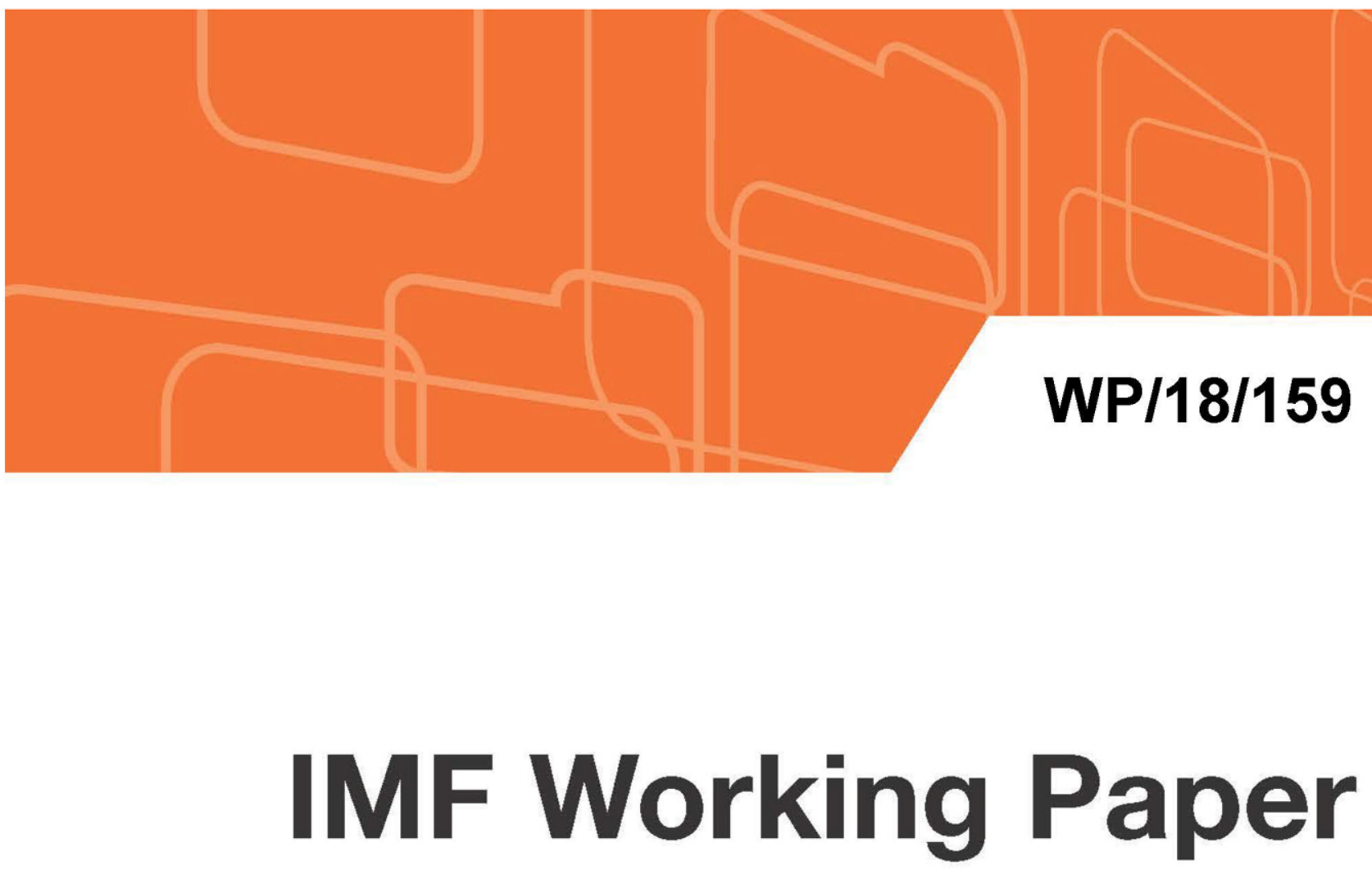

\title{
Losing to Blackouts: Evidence from Firm Level Data
}

by Daniel Gurara and Dawit Tessema

IMF Working Papers describe research in progress by the author(s) and are published to elicit comments and to encourage debate. The views expressed in IMF Working Papers are those of the author(s) and do not necessarily represent the views of the IMF, its Executive Board, or IMF management. 


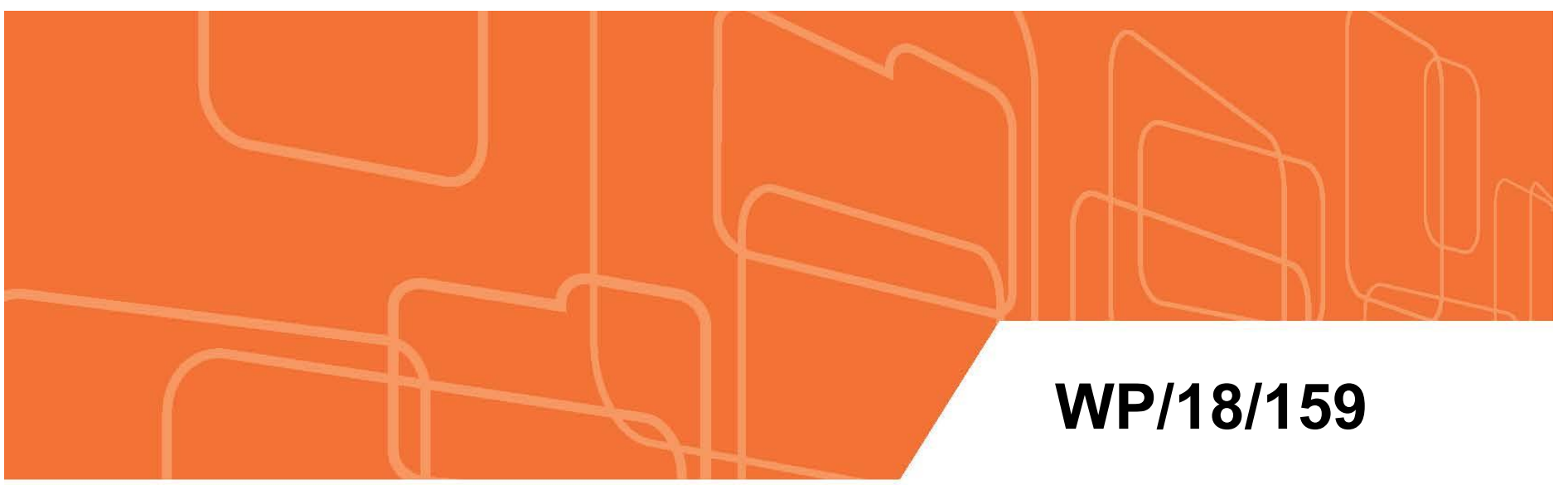

\section{IMF Working Paper}

\section{Losing to Blackouts: Evidence from Firm Level Data}

by Daniel Gurara and Dawit Tessema

IMF Working Papers describe research in progress by the author(s) and are published to elicit comments and to encourage debate. The views expressed in IMF Working Papers are those of the author(s) and do not necessarily represent the views of the IMF, its Executive Board, or IMF management.

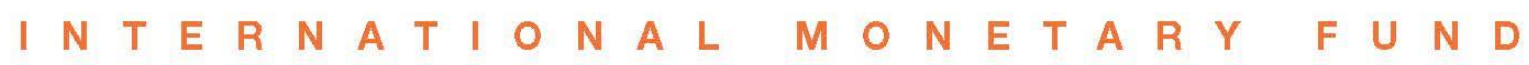




\title{
IMF Working Paper
}

Strategy, Policy, and Review Department

\section{Losing to Blackouts: Evidence from Firm Level Data ${ }^{1}$ \\ Prepared by Daniel Gurara and Dawit Tessema}

Authorized for distribution by Ali Mansoor

July 2018

\section{IMF Working Papers describe research in progress by the author(s) and are published to} elicit comments and to encourage debate. The views expressed in IMF Working Papers are those of the author(s) and do not necessarily represent the views of the IMF, its Executive Board, DFID or IMF management.

\begin{abstract}
Many developing economies are often hit by electricity crises either because of supply constraints or lacking in broader energy market reforms. This study uses manufacturing firm census data from Ethiopia to identify productivity losses attributable to power disruptions. Our estimates show that these disruptions, on average, result in productivity losses of about 4-10 percent. We found nonlinear productivity losses at different quantiles along the productivity distribution. Firms at higher quantiles faced higher losses compared to firms around the median. We observed patterns of systematic shutdowns as firms attempt to minimize losses.

JEL Classification Numbers: D24, E24, L43

Keywords: Power disruption, Productivity loss, Shutdowns

Authors’ E-Mail Addresses: DGurara@,imf.org, DTessema@imf.org

\footnotetext{
${ }^{1}$ Authors acknowledge the support from U.K.'s Department for International Development (DFID) under the project, Macroeconomic Research in Low-Income Countries. The views expressed here are those of the authors and do not necessarily represent those of the IMF, IMF policy, or DFID. We thank for helpful comments, Zidong An, Gabriele Ciminelli, Stefania Fabrizio, Roland Kpodar, Futoshi Narita, Andrea Presbitero, and seminar participants at the Development Issues Unit and AFR Inclusive Growth Network.
} 


\section{Contents}

1 Background $\quad \underline{5}$

2 A Brief History of Outages $\quad \underline{7}$

3 Conceptual Framework and Data $\underline{8}$

3.1 Conceptual Framework ................ $\underline{8}$

3.2 Data .......................... 11

4 Empirical Strategy $\quad \underline{14}$

4.1 Estimating the Productivity Cost of Power Disruptions . . . . . . . . . 14

4.2 Firm Response to Outages . . . . . . . . . . . . . . . . 17

5 Results and Discussion $\quad \underline{18}$

5.1 How Costly are Power Disruptions? . . . . . . . . . . . . . . 18

5.2 Do Firms Shutdown to Avoid Bigger Losses? . . . . . . . . . . . . . . 26

6 Concluding Remarks $\quad \underline{30}$

Appendices $\quad \underline{35}$

A Unbalanced panel results $\quad \underline{35}$

B Balanced panel results $\quad \underline{43}$

\section{List of Figures}

1 A Decision Tree of Firms' Responses to Power Disruption. . . . . . . . $\underline{9}$

2 Alternative Power Disruption Measures . . . . . . . . . . . . 13

3 The Productivity Loss from Electricity Disruptions . . . . . . . . . . . . $\underline{22}$

4 Productivity Loss from Power Disruptions . . . . . . . . . . . $\underline{23}$

5 Productivity Loss Due to Power Disruptions (aggregate TFP) . . . . . . . $\underline{26}$

6 Shutdown Incidents Vary by Age . . . . . . . . . . . . . . 27

A.1 Productivity Loss from Electricity Disruptions (Table 4, IV model: Col 8) . . . $\underline{36}$

A.2 Within-industry Productivity Loss Due to Power Disruptions . . . . . . 39

(C) International Monetary Fund. Not for Redistribution 
A.3 Within-industry Productivity Loss Due to Power Disruptions . . . . . . $\underline{42}$

A.4 Productivity Loss from Electricity Disruptions . . . . . . . . . . . . . . $4 \underline{44}$

A.5 Productivity Loss from Electricity Disruptions . . . . . . . . . . . $\underline{45}$

\section{List of Tables}

1 Total Number of Firms by ISIC-2 . . . . . . . . . . . . . . . 12

2 Summary Statistics . . . . . . . . . . . . . . . 13

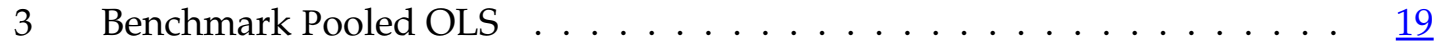

4 Fixed Effects and IV Estimation $\ldots \ldots \ldots \ldots \ldots$

5 Panel Quantile Regression (aggregate) $\ldots \ldots \ldots \ldots \ldots \ldots$

6 Panel Quantile Regression (within-industry) . . . . . . . . . . . . . $\underline{25}$

7 Negative Binomial Regression . . . . . . . . . . . . . . $\underline{29}$

A.1 Unreliability of Utility Services to Manufacturing Firms . . . . . . . . . $\underline{35}$

A.2 Electricity Cost as a Share of Total Industrial Cost . . . . . . . . . . . $\underline{35}$

A.3 Correlation Between $S^{\sigma}$ and Possible Reasons for Lower Power Consumption . .35

A.4 Estimated Productivity Losses from Table $4 \ldots \ldots \ldots$

A.5 Fixed Effects and IV Estimation (with $\left.S^{\sigma}\right) \ldots \ldots \ldots \ldots$

A.6 Estimated Productivity Losses from Table A.5 . . . . . . . . . . . . . $\underline{37}$

A.7 Aggregate Production Functions . . . . . . . . . . . . $\underline{38}$

A.8 Industry Level Production Functions $(\mathrm{LP}) \ldots \ldots \ldots \ldots \ldots \ldots \ldots \ldots$

A.9 Industry Level Production Functions $(\mathrm{ACF}) \ldots \ldots \ldots \ldots$

A.10 Industry Level Production Functions (LP) . . . . . . . . . . . . . 39

A.11 Industry Level Production Functions $(\mathrm{ACF}) \quad \ldots \ldots \ldots$. . . . . . . 39

A.12 Poisson Models . . . . . . . . . . . . . . . . . . . .

A.13 Alternative to Count Models-Pooled OLS . . . . . . . . . . . . . . . . $\underline{41}$

A.14 Panel Quantile Regressions (using ACF) . . . . . . . . . . . . . . . 41

A.15 Fixed Effects and IV Estimation (balanced panel) . . . . . . . . . . . $\underline{43}$

A.16 Estimated Productivity Losses from Table A.15 . . . . . . . . . . . . $\underline{43}$

A.17 Fixed Effects and IV Estimation (balanced panel) . . . . . . . . . . $\underline{44}$

A.18 Estimated Productivity Losses from Table A.17 . . . . . . . . . . . $\underline{45}$

(C) International Monetary Fund. Not for Redistribution 


\section{Background}

Power disruptions inflict non-trivial welfare loss in developing countries (Alam, 2013; Allcott et al., 2016; Zuberi, 2012). Measuring these losses is often challenging for two reasons. First, it is unlikely that firms absorb the full cost of disruptions but rather adopt coping mechanisms to minimize large losses (Steinbuks and Foster, 2010; Fisher-Vanden et al., 2015). Ignoring these investments can introduce an upward bias to real cost estimates. Second, lack of data makes it difficult to account for adaptation costs such as generator ownership that sharply increase energy costs relative to grid electricity. Picking up on such missing pieces is crucial to avoid underestimating the cost of disruptions.

Evidence on the productivity impact of power disruptions is scant. Past studies focused on cyclical revenue losses or cost escalation due to disruptions. Particularly, the shortterm focus can understate the impact of these disruptions, especially if firms tap into inventories to smooth out short-term losses. We look beyond the short-term and focus on productivity losses since the prospect of continued disruptions can tie up firm resources in unproductive mitigation measures with consequences for long-term productivity. Recent studies go beyond short-term loss and look at impacts on job creation (Mensah, 2018) and tax mobilization in Africa (Blimpo et al., 2018); and firm productivity in India and Pakistan (Allcott et al., 2016; Grainger and Zhang, 2017).

We attempt to fill these gaps by quantifying productivity losses accrued to power disruptions using manufacturing firm data from Ethiopia over 2000 - 2009. We contribute to the literature by looking at links between power disruptions, their costs and how the two influence firm shutdown episodes. To help us examine these links, we focused on three interrelated questions: [a] how much productivity is lost due to electricity shortages? [b] do productivity losses vary with the intensity of electricity use? and [c] are firms likely to temporarily shutdown to avoid large losses?

Our empirical strategy relies on two complementary proxies for power outage as the survey does not directly measure power losses. First, we constructed a dummy for power disruptions when firms identify electricity disruption as a major challenge to their oper-

(C) International Monetary Fund. Not for Redistribution 
ation in a fiscal year. Drawing on this and other firm specific information, we estimated productivity differences when disruptions are a major constraint and when they are not. Firms, however, can form opinions about their biggest challenges after observing productivity levels. We use deviation of firms' grid-power consumption from its long-run trend as an alternative proxy to address potential endogeneity bias from the first measure. As the data shows, this measure is not strongly correlated with other distortions that could cause lower grid-power consumption such as raw material and machinerypart shortages. Labor productivity and TFP are used as alternative productivity measures. Additionally, we examine how frequently temporary shutdowns are used to minimize losses from power disruptions. We tested whether these 'incidents' are related to power disruptions while controlling for firm specific heterogeneity.

Our results show that electricity disruption has a significant effect on productivity, irrespective of productivity measures. Labor productivity is, on average, 6 - 10 percent lower due to power disruptions. The result is similar when TFP is used to measure productivity. The equivalent loss in TFP averaged between 4 - 9 percent, after controlling for relevant covariates and firm level heterogeneity. However, losses are non-linear varying by intensity of power use and productivity quantile. Productivity losses are high at higher quantiles. Similar patterns are observed along different intensities of power use. Furthermore, we show that firms could temporarily shut down to lower losses from power disruptions, on average, by 1.4 - 2 months.

Our results are consistent with a growing empirical evidence on the economic cost of electricity disruptions (Alam, 2013; Allcott et al., 2016; Fisher-Vanden et al., 2015; Zuberi, 2012). Each of these studies estimated the impact of disruptions on either revenues and costs, or the use of alternative energy sources. Fisher-Vanden et al. (2015) showed energy intensive firms in China faced 13 percent higher costs due to electricity disruptions. Similarly, Allcott et al. (2016) found a 5-10 percent reduction in the revenues of Indian manufacturing firms and much smaller productivity losses because input storage is possible. However, different industries could face different costs. Alam (2013) shows how steel mill output in India fell by 11-16 percent in response to a 10 percent increase in outages. Rice mills avoid output loss by altering production speed and/or technology.

(C) International Monetary Fund. Not for Redistribution 
The rest of the paper is organized as follows. Section 2 provides a succinct history of power outages in Ethiopia. Section 3 summarizes the conceptual framework used to think through firm response to outages and briefly introduces the data. Section 4 describes the empirical strategy. The first part of section 4 introduces two approaches used to estimate the productivity cost of outages. The second part explains why firms could respond to outages by varying capacity utilization. Sections 5 presents results and discussions, and section 6 concludes.

\section{A brief history of outages}

Perhaps one of the most pressing challenges facing the Ethiopian economy is maintaining the structural integrity of power generation networks. The power system came under severe strain over the past decade due to distribution system maintenance backlogs, delays with bringing in new generating capacity, and unanticipated weather shocks. As a result, the state owned utility provider, Ethiopian Electric Power Corporation (EEPCo), relied on variable load shedding schedules to deal with the problem (EEA, 2009).

At the height of the power crisis in 2009, EEPCo estimated peak hour generating capacity shortfall of 19 percent (FDRE, 2012). While the majority of power outages last only a few hours, some last for days forcing manufacturing firms to close their doors. But, extreme cases of nationwide load shedding involving deep power cuts are not rare. One case of such extreme rationing occurred in April 2009, where outages were spread-out over six days and lasted 14 hours each time (EIU, 2009a). These restrictions were further tightened in May 2009 where the country's three large cement plants were advised to close for 30 days. Additionally, nearly 100 other power intensive plants were flagged and absorbed deep cuts, exemption granted to exporters was revoked and scheduled cuts for other users were extended to eight days a month (EIU, 2009a).

Such recurring blackouts have inflicted large economic costs. Engida et al. (2011) estimated losses reaching 3.1 percent of GDP during 2002-2004 using a static Computable General Equilibrium Model. The study suggested that the government's decision to favor a handful of export oriented activities may have led to a higher overall cost com- 
pared to a "no-favorites" strategy. An anecdotal study by EIU estimated the cost of the 2009 blackouts at 3.5 percent of GDP (EIU, 2009b). These estimates included the cost of lost production and imports of 200,000 tonnes of cement to compensate for temporary cessation of local production. Also reflected in the estimates are independent generation by large private firms, and costs incurred to foreign-private sector contractors commissioned by EEPCo to supply diesel generators for half of the outage period.

According to World Bank Enterprise Surveys, the number of firms reporting power disruptions as major constraint is rising (World Bank, 2015). In 2011, 63 percent of firms reported electricity disruptions as an obstacle to their operations with 33 percent of firms reporting it a major/severe obstacle. In 2015, this number climbed to 87 percent with 42 percent of all firms reporting it as a major obstacle. Broader comparison with SSA reveals a sharper resemblance. Particularly, the proportion of firms reporting outages and the duration and frequency of those outages are strikingly similar. Annex Table A.1 elucidates these similarities.

Own generation of electricity is small although a non-trivial number of firms own generators and intend to supplement grid electricity should disruptions occur. While the number of firms owning or sharing generators is roughly 42 percent, self generation accounts for less than 17 percent of total electricity consumption (World Bank, 2015). Some firms keep generators for periods of severe power disruptions and ride out shortlived outages. Self generation is used as a last resort since it is often more costly than grid electricity (Alby et al., 2013). Self-generated electricity could be three to four times more expensive than grid electricity (Steinbuks and Foster, 2010).

\section{Conceptual framework and Data}

\subsection{Conceptual Framework}

Power generation and distribution in Ethiopia is entrusted to the state utility company. Therefore, customers do not have the option to choose alternative power suppliers. Absent retail choice, able firms adopt coping mechanisms when faced with power disrup- 
tions, while others absorb the full cost of outages. We use a simple decision tree summarized by Figure 1 to thinking through choices available to firms and what these mean for productivity losses.

Firms facing power disruptions could respond in two ways. Those that can insure themselves against losses do so by acquiring generators (Reinikka and Svensson, 2002). While this allows them to replace grid electricity and continue to produce throughout the year, installation of self-generation capacity ties up potentially productive capital $K$. In such cases, investment in complementary capital provides a temporary relief, but can reduce long-run output. The capacity to self-generate does not automatically guarantee complete substitution between grid and self-generated power.

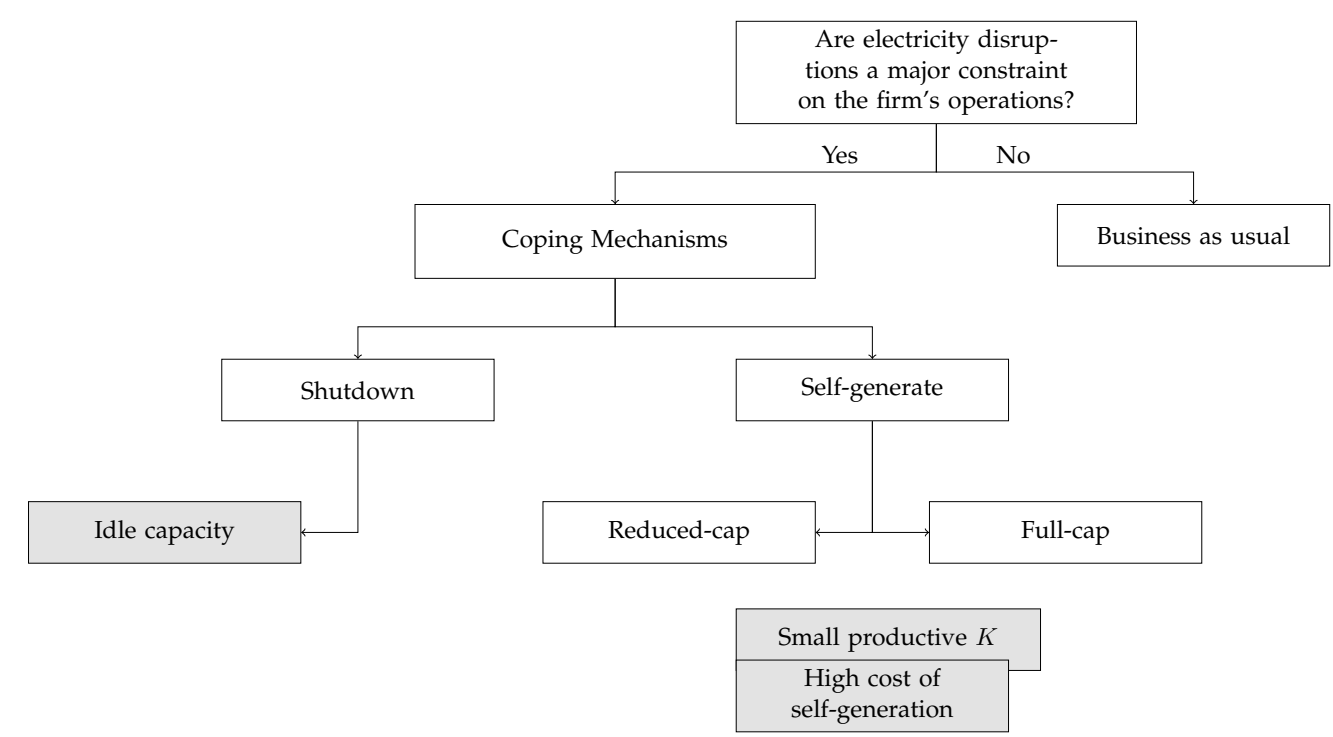

Figure 1: A decision tree of firms' responses to power disruption.

The economic burden imposed by self-generation might not be wholly offloaded to consumers through mark-ups especially if firms face elastic demand for their goods, or industry specific tariff rates are low enough to allow cheaper imports. This limits the potential of self-generation as a permanent substitute for unreliable public grid supply. Self-generation also affects investment options available to developing country entrepreneurs since it adds to capital and operating costs of doing business, raises production costs, lowers the competitiveness of local products, and limits the potential for exploiting economies of scale (Steinbuks and Foster, 2010). 
For these reasons, the self-generation option is often open only to medium and large firms. The majority of smaller firms either have small-scale operations making it too costly to own generators, or they are rationed out of credit markets that facilitate such investments. Small firms in these positions are forced to scale down when faced with unanticipated disruptions. Such firms could lower intermediate input demand, when labor markets are fragmented and capital is quasi-fixed. But more generally, small firms can minimize losses by either lowering flexible input demand and varying capacity utilization (over time), or through temporary shutdown.

We use alternative measures of power disruption to capture its impact on productivity and temporary shutdowns. The first measure ' $S$ ' is a dummy equal to one if the firm faced electricity disruption in a fiscal year. We distinguish between firms ranking the problem as a major constraint in a particular fiscal year 'shortage-firms' from those that do not 'non-shortage firms'. This designation is not fixed over time and time-variation in the dummy is crucial since a fixed designation could also flag inherent productivity problems that keep firms from adapting. The productivity losses computed in this study are a sum total of all conceivable costs.

One caution against the use of self-reported power disruption measures is they can underestimate the proportion of firms reporting disruptions. If generator owning firms are less likely to report power disruptions, then the self-reported power disruption measure is more likely to underestimate the reach of power disruptions. Nevertheless, the cost of owning and operating generators is substantially higher than grid supply that it would be unrealistic for generator owning firms to ignore such cost discrepancies. The other concern involves the timing of judgments about major constraints faced during a fiscal year. If firms decide major constraints to their operations after observing their productivities, then ' $S$ ' is endogenous.

We use an alternative proxy to address the drawbacks of the first measure. $S^{\sigma}$ is a dummy that captures all firms facing grid-power consumption drops exceeding ' 1 standard deviation' from long-run grid power consumption in any fiscal year. This includes firms that either cope with grid-power disruptions or incur its full cost. The data shows that this measure is not correlated with other distortions that might lower grid-power con- 
sumption such as raw material and machinery-part shortages (see Appendix Table A.3).

The conceptual framework broadly outlines a firm's responses to power disruptions. It specifically highlights the long-term implications of power disruptions by either creating and perpetuating idle capacity or tying up resources in unproductive capital. This feeds into our empirical analysis in two ways. First, it helps us quantify the productivity cost of power disruptions for a broad range of firms that vary by power use and productivity levels. Second, it helps us examine the link between recurring blackouts and firms' decisions to temporarily shut down to avoid losses.

\subsection{Data}

We use firm level manufacturing census data spanning 2000-2009 and our analysis is restricted to the 10 year period. All manufacturing firms in the country employing at least 10 workers and using electricity in production are surveyed as part of the Large and Medium Manufacturing Industries Survey (LMMIS). The census contains comprehensive information on number of employees, wages and salaries paid by firms, paid-up capital, industrial and non-industrial costs, value added, quantity and price of products and raw materials, fixed assets, investment and production capacity. The dataset has been used to examine firm location choice, behavior in the export sector and links between firm size and structural change (Bigsten et al., 2011; Söderbom, 2012; Shiferaw et al., 2015; Siba and Gebreeyesus, 2017).

Table 1 summarizes the distribution of Large and Medium Scale Manufacturing Industries by major Industrial groups. A large number of the firms operate in two sectors. Glass and non-Metallic mineral manufacturers and food and beverage producers accounted for 40-54 percent of the total, indicating firm concentration in a limited range of manufacturing activities. The same sectors accounted for the largest share of employment, employment growth and nearly half of the total value added of firms in the census. The number of firms in each industry group increased over time despite some irregular entry and exit patterns. The year 2005 is a notable exception where postelectoral uncertainties led to firm closures and temporary attrition. 
Table 1: Total Number of Firms by ISIC-2

\begin{tabular}{lcccccccccc}
\hline & 2000 & 2001 & 2002 & 2003 & 2004 & 2005 & 2006 & 2007 & 2008 & 2009 \\
\hline Food \& Beverage & 213 & 219 & 266 & 272 & 294 & 213 & 332 & 338 & 432 & 479 \\
Textile & 33 & 31 & 34 & 36 & 38 & 38 & 42 & 41 & 25 & 44 \\
Apparel & 25 & 24 & 29 & 32 & 35 & 28 & 31 & 32 & 34 & 37 \\
Leather Tanning \& footwear & 52 & 52 & 52 & 56 & 62 & 60 & 60 & 72 & 75 & 80 \\
Wood Products & 16 & 14 & 21 & 17 & 20 & 18 & 21 & 33 & 49 & 44 \\
Paper \& Paper Products & 7 & 5 & 7 & 7 & 7 & 9 & 12 & 12 & 19 & 18 \\
Publishing \& Printing & 56 & 46 & 66 & 66 & 66 & 68 & 74 & 81 & 92 & 87 \\
Chemicals & 39 & 36 & 41 & 45 & 45 & 51 & 52 & 64 & 70 & 69 \\
Rubber \& Plastics & 27 & 27 & 37 & 39 & 42 & 47 & 63 & 64 & 80 & 82 \\
Glass \& Non-metallic Minerals & 77 & 81 & 96 & 111 & 119 & 66 & 135 & 265 & 447 & 552 \\
Basic Iron, Steel, \& Casting & 7 & 10 & 11 & 10 & 13 & 13 & 14 & 13 & 14 & 15 \\
Metal Products & 50 & 50 & 61 & 73 & 73 & 73 & 95 & 57 & 93 & 104 \\
Machinery \& appliances & 13 & 7 & 7 & 9 & 9 & 6 & 8 & 4 & 3 & 4 \\
Motor vehicles \& accessories & 9 & 6 & 6 & 7 & 7 & 8 & 10 & 42 & 14 & 12 \\
Furniture & 113 & 112 & 147 & 157 & 165 & 63 & 187 & 197 & 264 & 299 \\
\hline Total & 738 & 721 & 882 & 938 & 996 & 762 & 1133 & 1314 & 1712 & 1922 \\
\hline
\end{tabular}

Appendix Table A.2 provides a summary of electricity cost as a share of total industrial cost. The intensity of electricity use is highest among non-metallic mineral manufacturers and textile and apparel producers. These firms are likely to feel the effect of frequent electricity disruptions than others. Also highlighted in the census are constraints faced by firms in the reference period. Firms are routinely asked to list three pressing constraints to their operations. Power disruptions are cited as one of three major constraints in 4 of the 10 years matching periods of nationwide load shedding programs. In 2009, nearly 36 percent of the firms cited electricity shortage as a major constraint. Far fewer firms cited demand related problems (8 percent), lack of working capital (3 percent) or foreign exchange shortages (1 percent).

Before proceeding to the results, it is useful to take an initial look at features of the data. Table 2 reports summary statistics for an unbalanced panel of 3280 firms. The gross value of output ' $y$ ' is deflated by the weighted index of product prices, while inputs are scaled by a weighted index of input prices. Capital is derived from its book value. Table 2 shows wide variance in both input use and output across firms. While firm age varies between 2 - 50 years, median employment is about 20 workers. Working capital, which measures firms' short-term financial health shows a great deal of variance both across firms and time. Within firm variance is much smaller in all relevant variables. 
Table 2: Summary Statistics

\begin{tabular}{lcccccc}
\hline & Mean & $\sigma_{i j}$ & P50 & Min & Max & N \\
\hline & & & & & & \\
Value-added (logs) & 13.67 & 2.22 & 13.31 & 10.74 & 19.61 & 10621 \\
Capital (logs) & 13.94 & 2.83 & 13.41 & 8.15 & 18.76 & 10621 \\
Inputs (logs) & 13.24 & 2.16 & 13.02 & 6.40 & 19.94 & 10621 \\
Labor & 61.62 & 95.75 & 20.00 & 10.00 & 376.00 & 10621 \\
Electricity (logs) & 9.73 & 2.06 & 9.42 & 3.40 & 16.99 & 8803 \\
Water (logs) & 7.48 & 1.84 & 7.47 & 1.12 & 15.01 & 9009 \\
Investment-Capital (\%) & 8.85 & 0.15 & 8.89 & 0 & 43.7 & 10919 \\
Working-capital (logs) & 13.75 & 2.10 & 13.40 & 4.49 & 20.67 & 10845 \\
Firm Age (years) & 16.22 & 14.36 & 11 & 2 & 50 & 11094 \\
Shutdown (months) & 1.71 & 2.78 & 0 & 0 & 11 & 11094 \\
Capacity Utilization (\%) & 52 & 0.59 & 60 & 11 & 100 & 10064 \\
\hline
\end{tabular}

Nearly 40 percent of firms were under 10 years old, while only 20 percent of firms were over the age of 30 years. Similarly, firm-inactivity (shutdown months) has a right skewed distribution with a zero median. While most firms operate throughout the year, some firms report shutting down in the fiscal year. Shutdown periods varied both within and across firms and capacity utilization has the same right skewed distribution. The median utilized capacity in the sample is about 60 percent.

Figure 2: Alternative power disruption measures

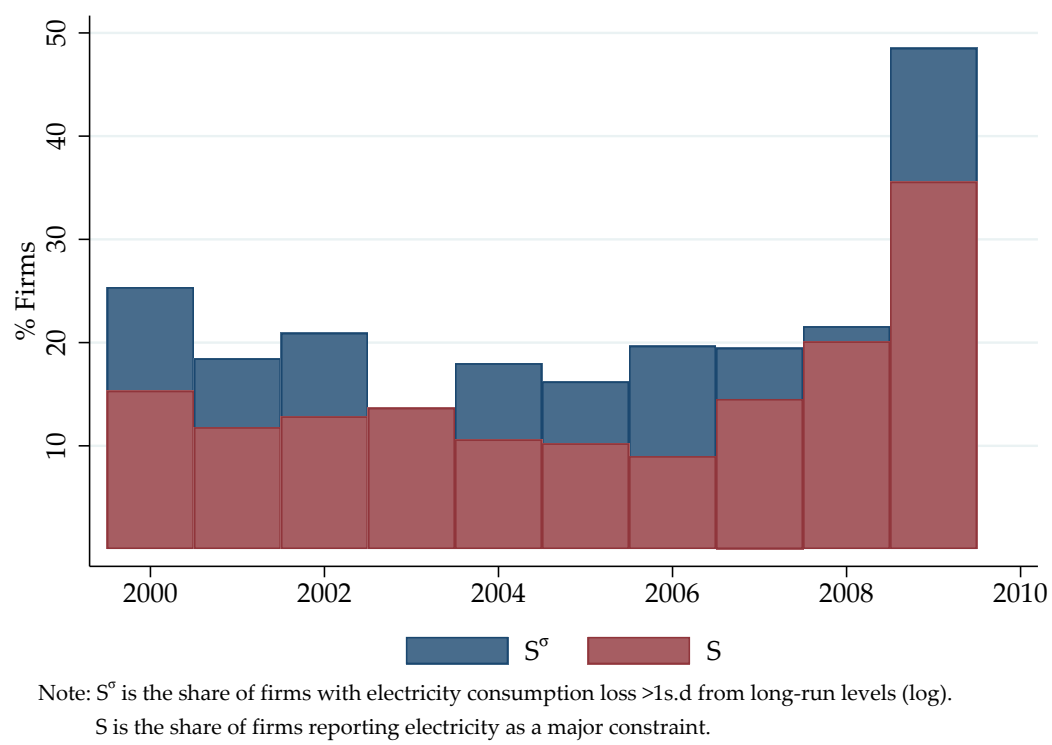

The share of firms reporting power disruptions as a major constraint gradually grew from below 15 percent of LMMI during 2000 - 2006 to nearly 25 percent in 2008 and 33 percent in 2009 (see figure 2). This trend is consistent with noteworthy blackout episodes 
discussed in Section 2. Also consistent with this trend is the increasing proportion of firms with electricity consumption (logs) below their long-run levels. The two power disruption measures track one another towards the end of the sample, but are generally weakly correlated. Except for 2003, the share of firms reporting power disruptions as major constraint is consistently lower than the grid-power consumption losses seen in the data $\left(S^{\sigma}>S\right)$. The difference $S^{\sigma}-S$ may be a rough approximation of firms that cope with power disruptions.

\section{Empirical Strategy}

\subsection{Estimating the productivity cost of power disruptions}

\section{Labor Productivity Losses}

We employ two approaches to measure the effect of power disruptions on firm productivity. In the first approach, we estimate productivity loss using a modified production function using a single-factor productivity measure and firm and time specific effects to control for unobserved productivity shocks. In the second approach, we use quantile regressions to estimate the losses to TFP productivity backed out of a production function ala Levinshohn and Petrin (2003) type control function regressions.

Consider a simple CRS Cobb-Douglas production function where $i$ and $t$ are firm and time indexes and $K_{i t}, L_{i t} E_{i t}$, and $M_{i t}$ are units of capital, labor, electricity, and raw materials. Suppose $\omega_{i t}$ summarizes attributes known to the firm (productivity shocks) such as managerial talent \& practice, human capital, or incentive pay. $\zeta_{i t}$ represents unobservable productivity shocks.

$$
Y_{i t}=\exp \left(\beta_{0}\right) L_{i t}^{\beta_{l}} K_{i t}^{\beta_{k}} M_{i t}^{\beta_{m}} E_{i t}^{\beta_{e}} \exp \left(\omega_{i t}\right)
$$

If the firm operates in a perfectly competitive output and input markets and observes $\omega_{i t}$ before optimally choosing inputs, then these input choices are also dependent on $\omega$. Several studies attempt to address this simultaneity problem to productivity measure- 
ment (Olley and Pakes, 1996; Levinshohn and Petrin, 2003; Ghandi et al., 2016; Ackerberg et al., 2015). Others extend the approach to the estimation of productivity when one or more inputs are measured with error (Collard-Wexler and De Loecker, 2016; Kim et al., 2016).

We simplify $E q(1)$ into a labor productivity equation by assuming output is produced at constant returns to scale and priced at marginal cost. Defining $\tilde{Y}_{i t}$ as labor productivity ${ }^{1}$, we can write $E q(1)$ as $\tilde{Y}_{i t}=\exp \left(\beta_{0}\right) \tilde{K}_{i t}^{\beta_{k}} \tilde{M}_{i t}^{\beta_{m}} \tilde{E}_{i t}^{\beta_{e}} \exp \left(\omega_{i t}\right)=\Phi(.) \exp \left(\omega_{i t}\right)$ and simplify further by defining $\phi($.$) as \phi()=.\ln \left[\exp \left(\beta_{0}\right) \tilde{K}_{i t}^{\beta_{k}} \tilde{M}_{i t}^{\beta_{m}} \tilde{E}_{i t}^{\beta_{e}}\right]$. We expanded the log-linearized labor productivity function by including alternative electricity disruption dummies $S_{i t}$ or $S_{i t}^{\sigma}$. $S_{i t}$ and $S_{i t}^{\sigma}$ represent, respectively, the number of firms reporting electricity disruptions as a major constraint, and firms with power loss exceeding $1 \mathrm{s.d}$ from long-run consumption. The parsimonious specification $E q(2)$ captures the average loss attributable to electricity disruption $\beta_{s}$, while $E q(3)$ picks up nonlinear effects due to differences in the use of electricity in manufacturing firms. The productivity loss due to electricity shortages is simply $1-\exp \left(\beta_{s}\right)$ percent in $E q(2)$ and $1-\exp \left(\beta_{S}+\beta_{\gamma} \tilde{e}+\beta_{\kappa} \tilde{e}^{2}\right)$ in $E q(3)$, where $\tilde{e}=\ln E-\ln L$.

$$
\begin{gathered}
\tilde{y}_{i t}=\phi(.)+\beta_{s} S_{i t}+\alpha_{j} \text { CONTROL }_{j i t}+\omega_{i t}+\zeta_{i t} \\
\tilde{y}_{i t}=\phi(.)+\beta_{\theta} \tilde{e}_{i t}^{2}+\beta_{s} S_{i t}+\beta_{\gamma} S_{i t} \times \tilde{e}_{i t}+\beta_{\varrho} S_{i t} \times \tilde{e}_{i t}^{2}+\alpha_{j} \text { CONTROL }_{j i t}+\omega_{i t}+\zeta_{i t}
\end{gathered}
$$

The empirical challenges discussed above suggest that an OLS regression of $E q(2)$ and $E q(3)$ will overestimate the $\beta^{\prime}$ s. For instance, if the firm gets a productivity boost (which it observes), such as an experienced manager economizing on input use, it can reduce raw-material use $\tilde{m}$ but at the same time expand productivity. OLS estimates will attribute all of the increase in productivity $\tilde{y}$ to the change in raw material use $\tilde{m}$, thus overestimating $\tilde{\beta_{m}}$. One way to deal with endogeneity bias caused by $\omega$ is to make some assumptions about unobserved heterogeneity. We assume that firm specific productivity shocks ' $\omega_{i t}$ ' are constant over time $\omega_{i t}=\omega_{i}$, all input choices are uncorrelated with the idiosyncratic error $\zeta_{i t} \sim \operatorname{iid}\left(0, \sigma_{\zeta}^{2}\right)$ and estimate the model using OLS once unobserved heterogeneity is differenced out. Firm age and working capital are used as addi-

\footnotetext{
${ }^{1} \tilde{K}_{i t}, \tilde{M}_{i t}$, and $\tilde{E}_{i t}$ are, respectively, the book value of fixed assets, raw-material and grid-power costs expressed in labor units. Lower-case letters represent log-equivalents of the same variables.
} 
tional control variables.

\section{Total Factor Productivity Losses}

If $\omega_{i}$ is "truly" fixed, then fixed effects estimation completely addresses selection and input endogeneity problems (Ackerberg et al., 2007). However, if unobserved productivity is not fixed, it is unlikely to capture heterogeneous responses to economic shocks. Fixed effects estimation could also generate worse estimates than standard OLS when there are measurement errors in inputs or when inputs are serially correlated over time (Griliches and Hausman, 1986). To overcome these problems, Olley and Pakes (1996) proposed a strategy of expressing unobserved productivity as a functions of observableproxies by making assumptions about the timing and dynamic nature of inputs -see Ghandi et al. (2016) for a comprehensive review. In the same tradition, we estimate the loglinearized production function $E q(1)$ using control function approaches by Levinshohn and Petrin (2003) (LP) and Ackerberg et al. (2015) (ACF) (see annex for brief descriptions). Raw material demand is used as the control function. Additional robustness checks are performed using electricity demand as a control function (see annex).

The best way to capture nonlinear effects in a simplified framework is to use a panel quantile regression technique. We use aggregate and industry specific TFP backed-out of $E q(5)$ and $E q(6)$ to estimate panel-quantile regressions with non-additive fixed effects (QRPD) ala Powell (2016). With quantile regressions, we are able to model any location within the productivity distribution, and get a complete picture of how power disruption affects firms. Traditional panel-quantile data estimators use additive fixed effects in a similar way as mean regressions, which makes it difficult to interpret estimated coefficients.

Powell (2016) addresses the problem by treating the likelihood of being in a productivity quantile as an unknown function of both firm fixed effect and an observationspecific disturbance term. The QRPD estimator has two notable advantages over other panel quantile methods. First, it provides point estimates that can be interpreted like cross-sectional regression results while allowing correlation between fixed effects and

CInternational Monetary Fund. Not for Redistribution 
covariates. Second, the number of estimated parameters is smaller since individual fixed effects are never estimated.

$$
\ln \left(\text { TFP }_{i t}\right)=\eta_{i t}(\tau)+\alpha_{s}(\tau) S_{i t}+\alpha_{s j}(\tau) C O N T R O L_{j i t}
$$

Estimation of parameters and standard errors is carried out using Markov Chain Monte Carlo Methods. The quantile treatment effect (QTE) $\alpha_{s}(\tau)$ represents the causal effect of a change in the treatment variable from $S_{i t}=0$ to $S_{i t}=1$ on $\ln \left(T F P_{i t}\right)$, given firm age and financial health, and holding fixed $\tau \in(0,1)$. We estimate Eq 7 using the alternative power disruption dummy $S^{\sigma}$.

\subsection{Firm response to outages}

The empirical literature shows varying firm responses to power disruptions. Rarely do firms assume the full cost of power disruptions. Capable firms, particularly, insure themselves against losses by self-generating power when grid electricity does not meet demand. Others cope by implementing systematic plant shutdowns. LMMIS allows us to examine the latter since each firm provides information about the number of months in operation in a reference year (rounded to the nearest natural number) and the value of output that could have been produced at full capacity computed at market price. This

gives us an estimate of underutilized capacity ${ }^{2} D_{i t}^{f}=\ln Y_{i t}^{F}-\ln Y_{i t}$ given actual output $Y_{i t}$ and full capacity output $Y_{i t}^{F}$.

Our interest is to analyze whether shutdown events are related to power disruption. We estimate this relationship using panel count-date models, as the dispersion of these incidents varies across firms for unobserved firm-specific reasons. Our response variable is 'number of months of shutdown' $I_{i t}$ over a firm's observed age, also known as the "incident" rate $r_{i t}$. Firm age is used as the exposure variable because younger firms tend to experience bouts of inactivity in the process of setting up their business unlike more mature firms and these bouts of inactivity may or may not be caused by market distortions.

\footnotetext{
${ }^{2}$ Capacity utilization could be measured with error if firms underreport revenue or potential revenue, or one by more than the other.
} 
We define shutdown/inactivity months $I_{i t}$ as $I_{i t}=12-A_{i t}$ for every active months of

operation $A_{i t}$. Finally, the "incident" rate $r$ is defined as $r_{i t}=\frac{I_{i t}}{A g e}$. Inactivity is independent and follows a Poisson distribution: $I_{i t} \sim \mathcal{P}\left(r_{i t} \times A g e_{i t}\right)$, where $\mathbb{E}\left(I_{i t}\right)=r_{i t} \times A g e_{i t}$. The "incident" rate is specified as an exponential function of past capacity underutilization, past productivity and current electricity shortage:

$$
\begin{gathered}
r_{i t}=\exp \left(\gamma_{s} S_{i t}+\gamma_{d} D_{i, t-1}^{F}+\gamma_{t} \ln T F P_{i, t-1}\right) \\
\mathbb{E}\left[I_{i t}\right]=\exp \left(\ln a g e_{i t}+\gamma_{s} S_{i t}+\gamma_{d} D_{i, t-1}^{F}+\gamma_{t} \ln T F P_{i, t-1}\right) \\
\ln \mathbb{E}\left[I_{i t}\right]=\ln \left(a g e_{i t}\right)+\gamma_{d} D_{i, t-1}^{F}+\gamma_{s} S_{i t}+\gamma_{t} \ln T F P_{i, t-1}
\end{gathered}
$$

\section{Results and Discussion}

We begin by reporting productivity cost estimates across various estimators in Section 5.1. Throughout the paper, we make comparisons of productivity loss estimates obtained by an OLS benchmark, against Fixed Effects, and control function approaches. Section 5.2 uses panel count data models to examine whether strategic shutdowns are influenced by power disruptions. Section B of the Appendix presents selected balanced panel results as additional robustness checks.

\subsection{How costly are power disruptions?}

\section{Labor productivity losses}

Table 3 summarizes pooled OLS benchmark regressions of $E q 2$ and Eq3. All standard errors in these regressions are clustered at the firm-level to allow for correlations of productivity shocks within firms and across time. Column (1) reports factor elasticities for a simplified productivity equation without added controls, where each factor is expressed in labor units. Elasticities of capital $\tilde{k}$, raw materials $\tilde{m}$, and electricity intensity $\tilde{e}$ are of acceptable magnitudes. Water-use has a negative elasticity due to a missing common trend as shown in Table 4. This fits a pattern where firms have learned to lower 
water-use while productivity improvements are taking place. Omitting the common trend could be responsible for the wrong sign.

Table 3: Benchmark pooled OLS

\begin{tabular}{|c|c|c|c|c|c|c|c|}
\hline \multirow[t]{2}{*}{ Output } & (1) & $(2)$ & (3) & (4) & (5) & (6) & (7) \\
\hline & \multicolumn{4}{|c|}{ Disruption $=S$} & \multicolumn{3}{|c|}{ Disruption $=S^{\sigma}$} \\
\hline Capital & $\begin{array}{c}0.10^{* * *} \\
(0.01)\end{array}$ & $\begin{array}{c}0.10^{* * *} \\
(0.01)\end{array}$ & $\begin{array}{c}0.10^{* * *} \\
(0.01)\end{array}$ & $\begin{array}{c}0.10^{* * *} \\
(0.01)\end{array}$ & $\begin{array}{c}0.11^{* * *} \\
(0.01)\end{array}$ & $\begin{array}{c}0.10^{* * *} \\
(0.01)\end{array}$ & $\begin{array}{c}0.10^{* * *} \\
(0.01)\end{array}$ \\
\hline Raw Materials. & $\begin{array}{c}0.63^{* * *} \\
(0.01)\end{array}$ & $\begin{array}{l}0.63^{* * *} \\
(0.01)\end{array}$ & $\begin{array}{c}0.60^{* * *} \\
(0.01)\end{array}$ & $\begin{array}{c}0.60^{* * * *} \\
(0.01)\end{array}$ & $\begin{array}{c}0.63^{* * *} \\
(0.01)\end{array}$ & $\begin{array}{l}0.60^{* * * *} \\
(0.01)\end{array}$ & $\begin{array}{c}0.60^{* * *} \\
(0.01)\end{array}$ \\
\hline Water & $\begin{array}{c}-0.02^{* * *} \\
(0.01)\end{array}$ & $\begin{array}{c}-0.02^{* * *} \\
(0.01)\end{array}$ & $\begin{array}{l}-0.01 \\
(0.01)\end{array}$ & $\begin{array}{l}-0.01 \\
(0.01)\end{array}$ & $\begin{array}{c}-0.02^{* * *} \\
(0.01)\end{array}$ & $\begin{array}{l}-0.01 \\
(0.01)\end{array}$ & $\begin{array}{l}-0.01 \\
(0.01)\end{array}$ \\
\hline Electricity & $\begin{array}{c}0.07^{* * *} \\
(0.01)\end{array}$ & $\begin{array}{c}0.07^{* * *} \\
(0.01)\end{array}$ & $\begin{array}{c}0.06^{* * *} \\
(0.01)\end{array}$ & $\begin{array}{l}-0.01 \\
(0.05)\end{array}$ & $\begin{array}{c}0.06^{* * *} \\
(0.01)\end{array}$ & $\begin{array}{c}0.05^{* * *} \\
(0.01)\end{array}$ & $\begin{array}{l}-0.03 \\
(0.06)\end{array}$ \\
\hline Electricity $^{2}$ & & & & $\begin{array}{c}0.01^{*} \\
(0.004)\end{array}$ & & & $\begin{array}{c}0.01 \\
(0.01)\end{array}$ \\
\hline Disruption & & $\begin{array}{c}-0.20^{* * *} \\
(0.02)\end{array}$ & $\begin{array}{c}-0.18^{* * *} \\
(0.02)\end{array}$ & $\begin{array}{l}-0.54^{*} \\
(0.28)\end{array}$ & $\begin{array}{c}-0.20^{* * *} \\
(0.02)\end{array}$ & $\begin{array}{c}-0.16^{* * *} \\
(0.02)\end{array}$ & $\begin{array}{l}-0.23 \\
(0.26)\end{array}$ \\
\hline Disruption $\times$ Electricity & & & & $\begin{array}{l}0.14^{*} \\
(0.09)\end{array}$ & & & $\begin{array}{c}0.06 \\
(0.08)\end{array}$ \\
\hline Disruption $\times$ Electricity $^{2}$ & & & & $\begin{array}{c}-0.013^{* *} \\
(0.01)\end{array}$ & & & $\begin{array}{l}-0.01 \\
(0.01)\end{array}$ \\
\hline Working capital & & & $\begin{array}{c}0.08^{* * *} \\
(0.02)\end{array}$ & $\begin{array}{c}0.08^{* * *} \\
(0.02)\end{array}$ & & $\begin{array}{c}0.04^{* * *} \\
(0.01)\end{array}$ & $\begin{array}{c}0.04^{* * *} \\
(0.01)\end{array}$ \\
\hline Age & & & $\begin{array}{l}0.23^{* * *} \\
(0.032)\end{array}$ & $\begin{array}{l}0.23^{* * *} \\
(0.032)\end{array}$ & & $\begin{array}{l}0.01^{* * *} \\
(0.001)\end{array}$ & $\begin{array}{l}0.01^{* * *} \\
(0.001)\end{array}$ \\
\hline Constant & $\begin{array}{c}3.81^{* * *} \\
(0.08)\end{array}$ & $\begin{array}{c}3.82^{* * *} \\
(0.08)\end{array}$ & $\begin{array}{l}4.07^{* * *} \\
(0.09)\end{array}$ & $\begin{array}{c}4.28^{* * *} \\
(0.19)\end{array}$ & $\begin{array}{c}3.79^{* * *} \\
(0.08)\end{array}$ & $\begin{array}{c}3.47^{* * *} \\
(0.09)\end{array}$ & $\begin{array}{c}3.70^{* * *} \\
(0.22)\end{array}$ \\
\hline Obs & 7,158 & 7,158 & 6,994 & 6,994 & 7,158 & 6,994 & 6,994 \\
\hline R-sq & 0.80 & 0.81 & 0.82 & 0.82 & 0.80 & 0.82 & 0.82 \\
\hline
\end{tabular}

Column (2) and (3) include additional control variables and a disruption dummy. The coefficient on the power disruption dummy is negative and statistically significant in both specifications. Shortage-firms have 14-18 percent lower labor productivity than non-shortage firms depending on which disruption dummy is used. These results should not be taken as evidence of a causal relationship since one or more of the left-hand side variables could be correlated with unobserved productivity shocks. We use these results as useful benchmarks to compare against alternative estimation strategies discussed in section 4.1. Column (4) and (7) include squared electricity intensity $\tilde{e}^{2}$ and interactions with the power disruption dummy. These additional coefficient estimates are marginally significant when $S_{i t}$ is the power disruption dummy indicating a non-linear relationship between productivity and power disruption working through the intensity of power use.

The pooled OLS point estimates are slightly different from the FE estimates presented in 
Table 4. Particularly, some point estimates are smaller -consistent with the predictions of simultaneity bias where observed inputs are correlated with unobserved shocks. The possible reduction in attenuation bias is captured by slightly higher FE point estimates of water $\tilde{\beta_{w}}$ and raw material use $\tilde{\beta_{m}}$ as shown in Table 4 . Again, column 1 reports factor elasticities for the simplified productivity equation including firm and year dummies, where each factor is expressed in labor units. Elasticities of capital $\tilde{k}$, raw materials $\tilde{m}$, and electricity intensity $\tilde{e}$ are of acceptable sign and magnitudes.

Fixed effects estimates of $\tilde{\beta}_{k}$ are much lower than the OLS benchmark. There are three equally plausible explanations for these low coefficients. First, FE estimates could be picking up only short-run effects since filtering out firm specific effects removes longrun variations in productivity. Higher OLS point estimates could mean a higher longrun impact of capital $\tilde{k}$. Durlauf and Quah (1999) offer a somewhat similar explanation. Second, it may be difficult to identify the marginal effect of capital using withinproducer time series variations if inputs such as labor and capital are fixed over a long period of time (Collard-Wexler and De Loecker, 2016). Measurement error in capital is the third possible explanation for smaller coefficients (Griliches and Hausman, 1986).

We used lagged investment per labor as an instrument for capital following the traditional error-in-variables structure. The basic assumption is that past investment is unlikely to be correlated with the measurement error. Columns 5 - 8 summarize the IV results. Although all elasticities still have the expected signs, the coefficient on working capital is no longer significant. Additionally, the coefficient on power disruption is only significant in the preferred specification. Despite these differences, the IV estimates imply much higher losses from power disruption as shown in Table A.4 and Figure A.1 (see Appendix). A standard Hausman test favors the IV estimates over the OLS (FE) estimates. However, the IV estimates come with a substantial loss of information due to a large number of observations with zero investment.

The power disruption dummies are negative, but significantly smaller than the OLS estimates. The average productivity loss from power disruptions is about 5 - 6 percent according to columns 2 and 3 compared to OLS average estimates of 17 - 18 percent in Table 3. Column 4 and 8 extend the specification to include interaction terms between 
Table 4: Fixed effects and IV estimation

\begin{tabular}{|c|c|c|c|c|c|c|c|c|}
\hline \multirow{3}{*}{ Output } & \multicolumn{4}{|c|}{$\mathrm{FE}$} & \multicolumn{4}{|c|}{ IV } \\
\hline & (1) & $(2)$ & (3) & (4) & (5) & (6) & (7) & $(8)$ \\
\hline & \multicolumn{8}{|c|}{ Disruption $=S$} \\
\hline \multirow[t]{2}{*}{ Capital } & $0.07^{* * *}$ & $0.07^{* * *}$ & $0.07^{* * *}$ & $0.07^{* * *}$ & $0.14^{* *}$ & $0.14^{* *}$ & $0.13^{* *}$ & $0.14^{* *}$ \\
\hline & $(0.01)$ & $(0.01)$ & $(0.01)$ & $(0.01)$ & $(0.06)$ & $(0.06)$ & $(0.06)$ & $(0.06)$ \\
\hline \multirow[t]{2}{*}{ Raw Materials } & $0.65^{* * *}$ & $0.65^{* * *}$ & $0.62^{* * *}$ & $0.62^{* * *}$ & $0.60^{* * *}$ & $0.60^{* * *}$ & $0.58^{* * *}$ & $0.57^{* * *}$ \\
\hline & $(0.02)$ & $(0.02)$ & $(0.02)$ & $(0.02)$ & $(0.03)$ & $(0.03)$ & $(0.03)$ & $(0.03)$ \\
\hline \multirow[t]{2}{*}{ Water } & $0.02^{* * *}$ & $0.02^{* * *}$ & $0.02^{* * *}$ & $0.02^{* * *}$ & 0.001 & 0.002 & 0.002 & 0.002 \\
\hline & $(0.01)$ & $(0.01)$ & $(0.01)$ & $(0.01)$ & $(0.01)$ & $(0.01)$ & $(0.01)$ & $(0.01)$ \\
\hline \multirow[t]{2}{*}{ Electricity } & $0.06^{* * *}$ & $0.06^{* * *}$ & $0.07^{* * *}$ & -0.07 & $0.04^{* * *}$ & $0.04^{* * *}$ & $0.05^{* * *}$ & -0.04 \\
\hline & $(0.01)$ & $(0.01)$ & $(0.001)$ & $(0.05)$ & $(0.02)$ & $(0.02)$ & $(0.02)$ & $(0.07)$ \\
\hline \multirow[t]{2}{*}{ Electricity $^{2}$} & & & & $0.01^{* * *}$ & & & & 0.01 \\
\hline & & & & $(0.004)$ & & & & $(0.01)$ \\
\hline \multirow[t]{2}{*}{ Disruption } & & $-0.05^{* * * *}$ & $-0.06^{* * *}$ & $-0.60^{* *}$ & & -0.04 & -0.04 & $-1.01^{* *}$ \\
\hline & & $(0.02)$ & $(0.02)$ & $(0.26)$ & & $(0.03)$ & $(0.03)$ & $(0.48)$ \\
\hline \multirow[t]{2}{*}{ Disruption $\times$ Electricity } & & & & $0.16^{* *}$ & & & & $0.29^{* *}$ \\
\hline & & & & $(0.08)$ & & & & $(0.14)$ \\
\hline \multirow[t]{2}{*}{ Disruption $\times$ Electricity $^{2}$} & & & & $-0.01^{* *}$ & & & & $-0.02^{*}$ \\
\hline & & & & $(0.01)$ & & & & $(0.01)$ \\
\hline \multirow[t]{2}{*}{ Working Capital } & & & $0.04^{* * *}$ & $0.04^{* * *}$ & & & 0.06 & 0.06 \\
\hline & & & $(0.03)$ & $(0.03)$ & & & $(0.08)$ & $(0.08)$ \\
\hline \multirow[t]{2}{*}{ Constant } & $4.17^{* * *}$ & $4.16^{* * *}$ & $4.23^{* * *}$ & $4.68^{* * *}$ & $4.24^{* * *}$ & $4.24^{* * *}$ & $4.23^{* * *}$ & $4.52^{* * *}$ \\
\hline & $(0.14)$ & $(0.14)$ & $(0.15)$ & $(0.21)$ & $(0.48)$ & $(0.48)$ & $(0.48)$ & $(0.56)$ \\
\hline Obs. & 7,158 & 7,158 & 6,994 & 6,994 & 2,397 & 2,397 & 2,372 & 2,372 \\
\hline R-sq. & 0.72 & 0.72 & 0.73 & 0.73 & 0.67 & 0.67 & 0.67 & 0.68 \\
\hline Firms & 2,360 & 2,360 & 2,331 & 2,331 & 981 & 981 & 976 & 976 \\
\hline Firm FE & YES & YES & YES & YES & YES & YES & YES & YES \\
\hline Year FE & YES & YES & YES & YES & YES & YES & YES & YES \\
\hline U-test (p-val) & - & - & - & 0.14 & - & - & - & 0.33 \\
\hline
\end{tabular}

the disruption dummy $S$, electricity intensity $\tilde{e}$, and its square. The coefficient on the intensity of power use is insignificant, but its square term is positive and significant (see column 4). Intuitively, the marginal productivity loss due to power disruption increases with power intensity $\tilde{e}$. Both the power disruption dummy and interaction terms are significant and indicate a possible non-linear relationship between productivity loss and the intensity of electricity use. We see slightly different non-linear patterns in Table A.5 when $S^{\sigma}$ is used as the disruption dummy (see Appendix).

We plotted predictions from the non-linear model (column 4) in Figure 3 to get a sense of the productivity loss from electricity disruptions at different intensities of power use across the two models. The left panel compares firm productivity $\tilde{y}$ at each intensity of power use $\tilde{e}$ with and without disruptions. This combination gives rise to the inverted "U" shaped productivity loss curve shown in the right panel. Losses at each intensity of use are computed as $1-\exp \left(\tilde{y}_{S}^{j}-\tilde{y}^{j}\right)$, where $\tilde{y}_{S}^{j}$ and $\tilde{y}^{j}$ are productivity levels at intensity $j$ with and without power disruption. Table A.4 summarizes these losses at each inten- 
Figure 3: The productivity loss from electricity disruptions
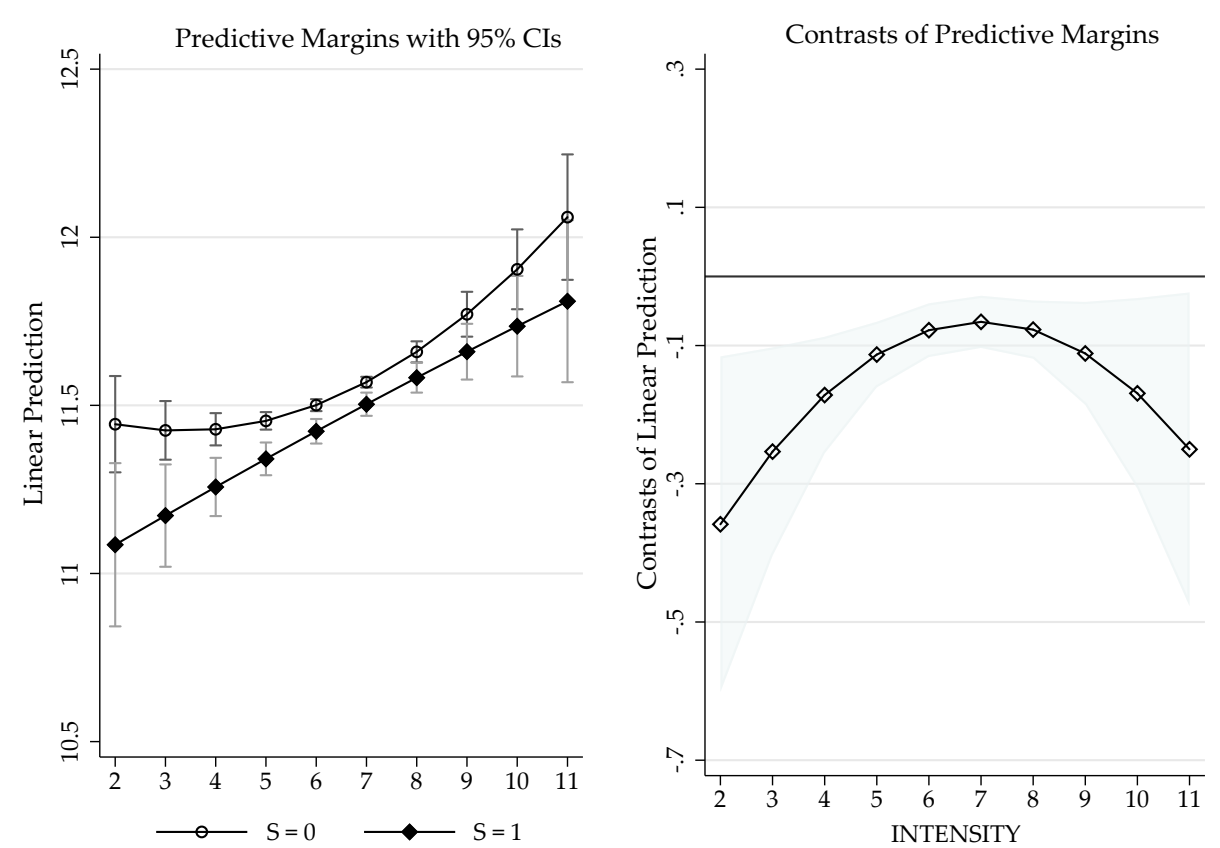

\begin{abstract}
Note: These are marginal effects from Table 4 Column 4 . The left panel plots a firm's predicted $\log$ labor productivity with and without power disruptions at different power use intensities $(\mathrm{x}$-axis INTENSITY=ẽ). The right panel plots the productivity differences with and without power disruptions at each intensity level $\ln \left(\frac{Y}{L} \mid S=1\right)-\ln \left(\frac{Y}{L} \mid S=0\right)$.
\end{abstract}

sity of use for the FE and IV estimates (see Appendix). The FE estimates yielded average productivity losses of 6-7 percent at mean intensity use, 22-30 percent at low intensity, and 16-22 percent at high intensity. The use of $S_{i t}^{\sigma}$ yields a different type of non-linear loss curve (see Appendix Table A.5 and Figure 4).

These productivity loss curves offer alternative interpretations. The inverted 'U-shaped' function, when ' $S$ ' is the power disruption measures, implies firms at the bottom end of the intensity curve find it prohibitively costly to adopt coping mechanisms. The initial investment in self-generation could be costly for smaller firms that are rationed out of formal credit markets. These firms might instead rely on strategic shutdowns to minimize the impact of disruptions. Large firms, by contrast, are likely to self-generate during severe disruption episodes. Higher productivity losses for such firms might indicate the high cost of self-generation. The downward sloping productivity loss function, when $S_{i t}^{\sigma}$ is the power disruption measures, offers a slightly different interpretation. Firms at higher intensities of power use face sharper losses due to disruptions than firms at lower intensity since firms at lower intensity find it easier to cope with power 
Figure 4: Productivity loss from power disruptions
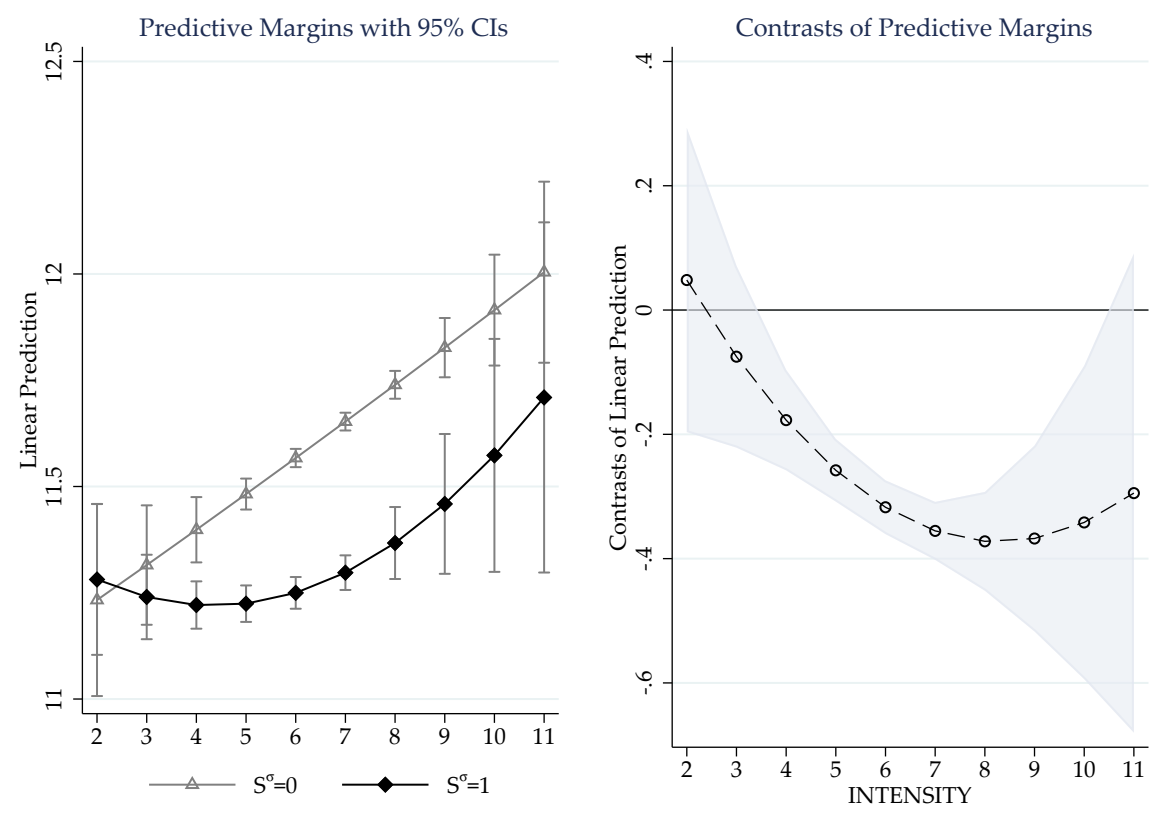

\begin{abstract}
Note: These are marginal effects from Table A.5 Column 3. The left panel plots a firm's predicted $\log$ labor productivity with and without power disruptions at different power use intensities $(\mathrm{x}$-axis INTENSITY $=\tilde{e})$. The right panel plots the productivity differences with and without power disruptions at each intensity level $\ln \left(\frac{Y}{L} \mid S^{\sigma}=1\right)-\ln \left(\frac{Y}{L} \mid S^{\sigma}=0\right)$.
\end{abstract}

disruptions either by switching away from power-using technology or other means.

Firms with power intensive processes, contrastingly, might face large adjustment costs if they are to switch to power saving technology.

\title{
Total factor productivity Losses
}

Labor productivity could overestimate productivity levels in large capital intensive firms even if all firms operated in identical factor markets. It is, moreover, possible for two firms to have different labor productivity levels while using the same production technology if factor intensities differ because of different factor prices. The use of total factor productivity minimizes these biases. We estimate the log-linearized production function Eq4 ala Levinshohn and Petrin (2003) (LP) and Ackerberg et al. (2015) (ACF) to back-out total factor productivity estimates ${ }^{3}$. The discussion in this section is centered on TFP estimates with raw material demand as the control function.

\footnotetext{
${ }^{3}$ The estimation utilizes a Stata module by Rovigatti and Mollisi (2016).
} 
Appendix Table A.7 presents factor elasticity estimates from the two control function approaches (LP and ACF). Columns 1 and 2 use raw-material demand as the control function. The results show wide variance in estimated elasticities between both approaches. LP estimates of labor and capital elasticities-column 1-are about half the values in the ACF alternative when raw materials are the control function (column 2). Alternatively, we divided firms into 5 industry groups that might use reasonably similar production technologies: chemical, glass and plastics (CGP); clothes and footwear (CAF); food and beverages (FAB); machinery, motors and accessories (MMA); and pulp, paper and publishing (PPP). Tables A.8-A.11 summarize industry group factor elasticity estimates from the two approaches (see Appendix). Again, estimated elasticities widely varied across industries and approaches. These variations serve as useful robustness checks.

We computed four alternative aggregate TFP estimates and four industry specific TFP estimates from the first stage regressions summarized in Appendix Tables A.7-A.11. Then, we use panel-quantile techniques in the second stage to quantify the impact of power disruptions on these TFP estimates. Markov Chain Monte Carlo (MCMC) methods are used to estimate Eq. ${ }^{4}$. Since MCMC methods involve random sampling, we do not obtain the same set of MCMC draws each time the procedure is carried out. We compare quantile estimates from several iterations to preserve a fair degree of precision in terms of Monte Carlo error (Liu et al., 2016).

Table 5 summarizes panel quantile regressions at the median of the productivity distribution. The dependent variables in these regressions are TFP estimates across all industry groups (in natural logs). For easy reference We call these estimates aggregate TFP. We use 50,000 MCMC draws at each quantile in order to achieve a desired degree of precision for the credible intervals. Columns 1 - 3 use TFP estimates from LP and, similarly, columns 4 - 6 use TFP estimates from ACF. The power disruption dummy point estimates is nearly twice higher for ACF compared to LP estimates. Columns 1 - 3 indicate an average productivity loss of 5-6 percent due to power disruptions, while losses are nearly 9 percent of TFP for the ACF alternative.

\footnotetext{
${ }^{4}$ The procedure is carried out using a new Stata module by Powell et al. (2016).
} 
Table 5: Panel quantile regression (aggregate)

\begin{tabular}{|c|c|c|c|c|c|c|}
\hline & \multicolumn{3}{|c|}{$\ln T F P_{L P}$} & \multicolumn{3}{|c|}{$\ln T F P_{A C F}$} \\
\hline & (1) & (2) & (3) & $(4)$ & (5) & (6) \\
\hline \multirow[t]{2}{*}{ Disruption } & $0.06^{*}$ & $-0.05^{* *}$ & $-0.05^{*}$ & 0.02 & $-0.09^{* * * *}$ & $-0.09^{* * *}$ \\
\hline & $(0.03)$ & $(0.02)$ & $(0.03)$ & $(0.02)$ & $(0.03)$ & $(0.03)$ \\
\hline \multirow[t]{2}{*}{ Age $\times 100$} & & $-0.43^{* * *}$ & -0.30 & & $-1.40^{* * * *}$ & $-1.39^{* * *}$ \\
\hline & & $(0.002)$ & $(0.003)$ & & $(0.003)$ & $(0.003)$ \\
\hline \multirow[t]{2}{*}{ Working Capital } & & $0.56^{* * *}$ & $0.54^{* * *}$ & & $0.36^{* * *}$ & $0.35^{* * *}$ \\
\hline & & $(0.01)$ & $(0.04)$ & & $(0.02)$ & $(0.02)$ \\
\hline Obs & 8,387 & 8,184 & 8,184 & 8,387 & 8,184 & 8,184 \\
\hline Firms & 2,686 & 2,649 & 2,649 & 2,686 & 2,649 & 2,649 \\
\hline Proxy & Raw Mat. & Raw Mat. & Raw Mat. & Raw Mat. & Raw Mat. & Raw Mat. \\
\hline
\end{tabular}

Table 6: Panel quantile regression (within-industry)

\begin{tabular}{|c|c|c|c|c|c|c|}
\hline & \multicolumn{3}{|c|}{$\ln T F P_{L P}$} & \multicolumn{3}{|c|}{$\ln T F P_{A C F}$} \\
\hline & (1) & (2) & (3) & $(4)$ & (5) & (6) \\
\hline \multirow[t]{2}{*}{ Disruption } & 0.05 & $-0.07^{* * *}$ & $-0.07^{* * *}$ & $-0.03^{*}$ & -0.02 & -0.02 \\
\hline & $(0.04)$ & $(0.02)$ & $(0.02)$ & $(0.02)$ & $(0.01)$ & $(0.02)$ \\
\hline \multirow[t]{2}{*}{ Age $\times 100$} & & $-0.70^{* *}$ & $-0.69^{* *}$ & & $-0.53^{* * *}$ & $-0.50^{* * *}$ \\
\hline & & $(0.003)$ & $(0.003)$ & & $(0.001)$ & $(0.001)$ \\
\hline \multirow[t]{2}{*}{ Working Capital } & & $0.52^{* * *}$ & $0.52^{* * *}$ & & $0.04^{* * *}$ & $0.04^{* * *}$ \\
\hline & & $(0.02)$ & $(0.02)$ & & $(0.01)$ & $(0.01)$ \\
\hline Obs & 8,378 & 8,176 & 8,176 & 10,149 & 9,935 & 9,935 \\
\hline Firms & 2,684 & 2,647 & 2,647 & 2,995 & 2,958 & 2,958 \\
\hline Proxy & Raw Mat. & Raw Mat. & Raw Mat. & Raw Mat. & Raw Mat. & Raw Mat. \\
\hline
\end{tabular}

Similarly, Table 6 summarizes the results for within-industry firm TFP estimates at the median of the distribution. Columns 1 - 3 report industry specific TFP losses estimates from LP, while columns 4 - 6 report TFP losses due to disruption for ACF corrected productivity estimates. Again power disruptions have similar effects on productivity across the two measures, and the aggregate firm TFP estimates (see Appendix Figure A.5 for within industry productivity losses for the alternative power disruption dummy). Specifically, the first three point estimates indicate an average productivity loss of 7 percent due to power disruptions. These estimates are not substantially different from those obtained when aggregate TFP measures were used.

Figure 5 maps marginal effects of power disruptions at different points in the productivity distribution. The left panel reports the marginal effect of power disruptions on aggregate TFP estimates from column 3 of Table 5. Similarly, the right panel plots the 
relationship based on columns 6 . Both panels offer the familiar inverted 'U'-shaped productivity loss curve. Firms at lower productivity quantiles $Q_{10}$ experience about 6 percent loss due to disruptions, while upper quantiles incur about 7-8 percent in TFP losses due to these disruptions. Again, the shape of the loss curve changes with $S_{i t}^{\sigma}$ (see Appendix Table A.14 and Figure A.5).

Figure 5: Productivity loss due to power disruptions (aggregate TFP)

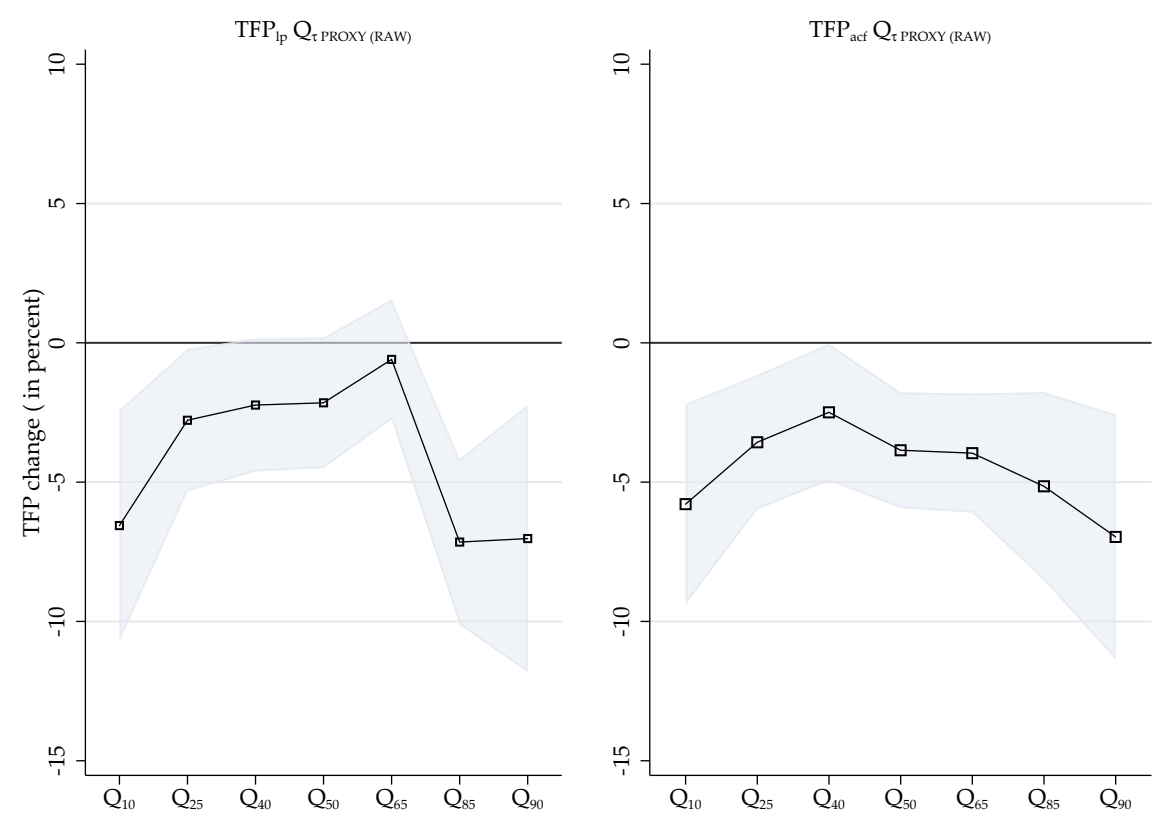

Note: Power disruption dummy $S$

\subsection{Do firms shutdown to avoid bigger losses?}

Without self-generation, strategic plant shutdowns may be the remaining viable coping mechanism available to smaller firms that are rationed out of formal credit markets. While temporary closure forestalls large losses, it might not eliminate costs incurred due to spoilage of inputs, labor costs, equipment breakdown and others. Large firms, by contrast, often have access to credit and can set-up their own generators and other facilities that shield them from losses due to power disruptions. In this section, we analyzed the relationship between observed shutdown incidents and power disruptions using panel count-outcome models.

Figure 6 shows shutdown frequencies, where the plot is divided into four panels with histograms summarizing plant shutdown episodes in four periods. The top-left panel 
Figure 6: Shutdown incidents vary by age

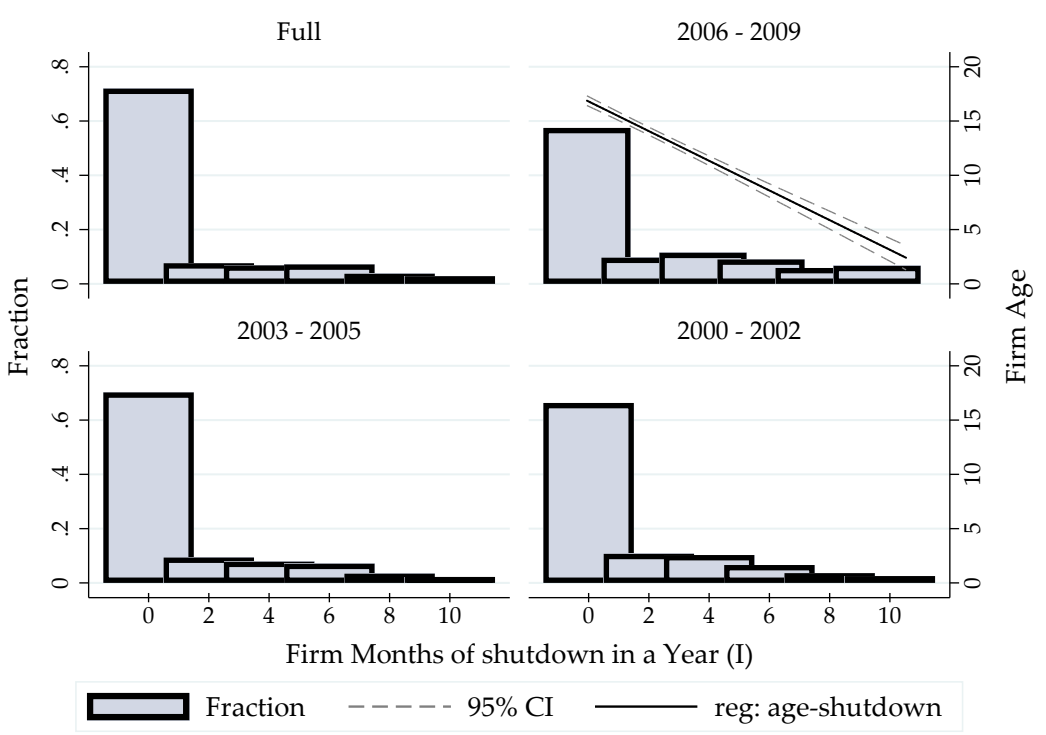

Note: The fitted values are from a linear regression of shutdowns ' $I$ ' on firm age.

shows plant shutdown episodes make up 37 percent of the full sample while frequency varied by period. Also captured is the relationship between firm age and shutdown incidents ' $I$ '. As expected, younger firms shutdown more often than mature firms. Drawing on this, we estimated an empirical model described in section 4.2 using two panelcount data models: Negative Binomial (NB) and Poisson models. Our response variable in NB regressions is the 'months of shutdown' $I_{i t}$ over a firm's observed age. We control for overdispersion by defining the "incident" rate $r_{i t}$ as the ratio $\frac{I_{i t}}{A g e}$. Firm age is used as the exposure variable because younger firms tend to experience bouts of inactivity in the process of setting up their business that may have very little to do with factor market distortions (e.g. trial production).

Table 7 and Table A.12 (Appendix) summarize results from the two sets of regressions. Poisson regression models for count-date are inherently heteroskedastic as the variance of the distribution moves in tandem with the mean. This feature poses a problem for the estimation of standard errors. Specifically, the standard errors of these quasi maximum likelihood estimations tend to underestimate true variability in the estimator and often lead to inflated t-statistics. Following recommended practice, bootstrapped standard errors are reported.

Table 7, columns 1 - 6 are random effects NB regressions, while Columns 7 - 12 are con- 
ditional fixed effects NB regressions. The results consistently show a positive and significant relationship between power disruptions and shutdown incidents. On average, firms are likely to shutdown operations for 1.4 - 2 months in response to power disruptions. These results remain strong after controlling for a history of unexploited capacity and lagged productivity. Firms that had large unexploited capacity in the past are more likely to shutdown than those that operated at full capacity. Shutdown incidents increased by about 1.3 months when unexploited capacity in the past year was 33\% higher ${ }^{5}$. Shutdown periods are much higher when unexploited capacity is larger. The results for the Poisson alternative offer similar conclusions (see Appendix Table A.12)

These results show a positive and significant relationship between power disruptions and shutdown incidents. Firms are likely to shutdown for $1.4-1.5$ months in response to power disruptions. Again firms with histories of idle-capacity are more likely to shutdown. Specifically, shutdown incidents in the current period increased by about 1.3 months in response to a 33 percent higher under-utilized capacity in the prior year. Productivity levels again are not useful predictors of shutdown episodes. This too is consistent across models and productivity concepts.

Differenced panel data models often have served as alternatives to count-data models. In the same tradition, we examined whether change in activity periods $A$, where $A=12-I$, varied with power disruption both across models and productivity concepts. Appendix Table A.13 summarizes key results from a differenced OLS model. Again these results consistently show a negative and significant effect of power disruptions on activity months. Power disruptions are likely to compel firms to shutdown for nearly 1 months. The results remain consistent when lagged second differences of productivity and excess capacity are used.

${ }^{5}$ A $33 \%$ increase in underutilized capacity is equivalent to 1 natural-log point increase in $D^{f}$. From see $E q 11$, the response in months is $\exp \left(\gamma_{s}\right)$. 
Table 7: Negative binomial regression

\begin{tabular}{|c|c|c|c|c|c|c|c|c|c|c|c|c|}
\hline \multirow[b]{2}{*}{$I$} & \multicolumn{6}{|c|}{ Random Effects Models } & \multicolumn{6}{|c|}{ Conditional Fixed Effects Models } \\
\hline & (1) & (2) & (3) & (4) & (5) & (6) & (7) & (8) & (9) & (10) & $(11)$ & (12) \\
\hline$S$ & $\begin{array}{l}0.61^{* * *} \\
(0.05)\end{array}$ & $\begin{array}{l}0.62^{* * *} \\
(0.1)\end{array}$ & $\begin{array}{l}0.67^{* * *} \\
(0.11)\end{array}$ & $\begin{array}{l}0.67^{* * *} \\
(0.10)\end{array}$ & $\begin{array}{l}0.69^{* * *} \\
(0.10)\end{array}$ & $\begin{array}{l}0.68^{* * *} \\
(0.08)\end{array}$ & $\begin{array}{l}0.57^{* * *} \\
(0.05)\end{array}$ & $\begin{array}{l}0.56^{* * *} \\
(0.10)\end{array}$ & $\begin{array}{l}0.63^{* * *} \\
(0.13)\end{array}$ & $\begin{array}{l}0.59^{* * *} \\
(0.11)\end{array}$ & $\begin{array}{l}0.60^{* * *} \\
(0.10)\end{array}$ & $\begin{array}{l}0.60^{* * *} \\
(0.11)\end{array}$ \\
\hline$D_{t-1}^{F}$ & & $\begin{array}{l}0.27^{* * *} \\
(0.05)\end{array}$ & $\begin{array}{l}0.29^{* * *} \\
(0.09)\end{array}$ & $\begin{array}{l}0.23^{* * *} \\
(0.06)\end{array}$ & $\begin{array}{l}0.28^{* * *} \\
(0.06)\end{array}$ & $\begin{array}{l}0.23^{* * *} \\
(0.06)\end{array}$ & & $\begin{array}{l}0.17^{* * *} \\
(0.07)\end{array}$ & $\begin{array}{l}0.13 \\
(0.08)\end{array}$ & $\begin{array}{l}0.14^{* *} \\
(0.07)\end{array}$ & $\begin{array}{l}0.15^{* *} \\
(0.06)\end{array}$ & $\begin{array}{l}0.15^{* * *} \\
(0.06)\end{array}$ \\
\hline $\ln T F P_{t-1}^{L P 1}$ & & & $\begin{array}{l}-0.1^{*} \\
(0.09)\end{array}$ & & & & & & $\begin{array}{l}-0.11 \\
(0.08)\end{array}$ & & & \\
\hline $\ln T F P_{t-1}^{A C F 1}$ & & & & $\begin{array}{l}-0.05 \\
(0.07)\end{array}$ & & & & & & $\begin{array}{l}-0.01 \\
(0.09)\end{array}$ & & \\
\hline $\ln T F P_{t-1}^{L P 2}$ & & & & & $\begin{array}{l}0.04^{*} \\
(0.08)\end{array}$ & & & & & & $\begin{array}{l}-0.05 \\
(0.09)\end{array}$ & \\
\hline $\ln T F P_{t-1}^{A C F 2}$ & & & & & & $\begin{array}{l}0.05 \\
(0.09)\end{array}$ & & & & & & $\begin{array}{l}0.11 \\
(0.09)\end{array}$ \\
\hline Const. & $\begin{array}{l}-1.99^{* * *} \\
(0.12)\end{array}$ & $\begin{array}{l}-2.61^{* * *} \\
(0.17)\end{array}$ & $\begin{array}{l}-2.92^{* * *} \\
(0.31)\end{array}$ & $\begin{array}{l}-2.74^{* * *} \\
(0.19)\end{array}$ & $\begin{array}{l}-3.15^{* * *} \\
(0.22)\end{array}$ & $\begin{array}{l}-2.90^{* * *} \\
(0.19)\end{array}$ & $\begin{array}{l}-2.66^{* * *} \\
(0.091)\end{array}$ & $\begin{array}{l}-3.10^{* * *} \\
(0.16)\end{array}$ & $\begin{array}{l}-3.09^{* * *} \\
(0.34)\end{array}$ & $\begin{array}{l}-3.26^{* * *} \\
(0.22)\end{array}$ & $\begin{array}{l}-3.01^{* * *} \\
(0.25)\end{array}$ & $\begin{array}{l}-3.70^{* * *} \\
(0.20)\end{array}$ \\
\hline Obs. & 11,094 & 6,431 & 4,856 & 6,040 & 6,040 & 6,044 & 6,418 & 3,353 & 2,151 & 3,071 & 3,071 & 3,075 \\
\hline Firms & 3,280 & 1,927 & 1,508 & 1,789 & 1,789 & 1,790 & 1,319 & 778 & 494 & 689 & 689 & 690 \\
\hline Log-Lik & -18320 & -9112 & -5829 & -8140 & -8136 & -8144 & -8149 & -3945 & -2506 & -3539 & -3539 & -3540 \\
\hline
\end{tabular}




\section{Concluding remarks}

Frequent power disruptions impose significant welfare loss in developing countries. Such distortions could have debilitating effects on nascent manufacturing sectors and stifle industrial development. This paper examined the productivity cost of power disruptions in Ethiopian manufacturing firms and their response to this perennial problem during 2000-2009. We used two alternative power disruption measures: one based on survey responses and the other on power consumption shocks.

Our estimates showed average productivity losses of 4 - 10 percent due to power disruptions. Firms with high intensities of electricity use suffered higher productivity losses than firms at the middle of the power use distribution depending on the measure of power disruption. We found similarly non-linear productivity losses at different quantiles along the productivity distribution. Specifically, firms with intensive power use suffered higher productivity losses than those at the median of the power use distribution. Similarly, power disruptions caused higher productivity loss at higher TFP quantiles than those at the median of the distribution.

We offered alternative explanations for higher productivity losses at upper productivity quantiles. First, productive firms exposed to power disruptions are likely to selfgenerate during severe disruptions. Higher productivity losses, therefore, might be due to high self-generation costs (Reinikka and Svensson, 2002). Second, firms with power intensive processes might face large capital adjustment costs if they want to switch to power saving technology. As a result, they end up absorbing some productivity losses. Third, firms are indirectly affected through local supply chain disruptions, especially to power intensive intermediate goods. This could result in decisions to lower capacity utilization.

Firms shield themselves against greater losses including by temporarily shutting-down plants. The evidence shows average factory closures ranging from 1.4 - 2 months in response to power disruptions. We find no relationship between plant shutdown decisions and productivity cohorts. This implies productive firms facing major power disruptions are as likely to rely on strategic shutdown as less productive ones. 
These results have clear policy implications. Broadly beneficial effects aside, maintaining an efficient power supply ensures productive firms remain productive. Not only does it shield firms from having to lock up resources in unproductive activities. It also limits involuntary coping mechanisms like variable capacity utilization or provisionally suspending operations to minimize losses. Therefore, the policy imperative for maintaining adequate, and efficient power supply is clear.

No two countries are exactly alike and variations introduced by cross-country differences are often useful to ensure generalizability. Absent comparable cross-country firm level panel data, country level analyses drawing on highlighted similarities in SubSaharan Africa is a convenient way to provide useful approximations. Additionally, the study can be an instructive input to future meta-analysis on the subject. 


\section{References}

Ackerberg, D., Caves, K. and Frazer, G. (2015), ‘Identification Properties of Recent Production Function Estimators', Econometrica 83(6), 2411-2451.

Ackerberg, D., Lanier, B., Berry, S. and Pakes, A. (2007), Econometric tools for analyzing market outcomes, in J. Heckman and E. Leamer, eds, 'Handbook of Econometrics', Vol. 6, Amsterdam: North-Holland, chapter 4, p. 4171-4276.

Alam, M. (2013), Coping with Blackouts: Power Outages and Firm Choices. Working Paper, Yale University.

Alby, P., Dethier, J. and Straub, S. (2013), 'Firms Operating under Electricity Constraints in Developing Countries', The World Bank Economic Review 27(1), 109-132.

Allcott, H., Collard-Wexler, A. and O'Connell, S. (2016), 'How Do Electricity Shortages Affect Industry? Evidence from India', American Economic Review 106(3), 587-624.

Bigsten, A., Gebreeyesus, M., Siba, E. and Söderbom, M. (2011), The Effects of Agglomeration and Competition on Prices and Productivity: Evidence for Ethiopia's Manufacturing Sector. University of Gothenburg Mimeo.

Blimpo, M., Mensah, J., Opalo, K. and Shi, R. (2018), Electricity Provision and Tax Mobilization in Africa. World Bank Policy Research Working Paper 8408.

Collard-Wexler, A. and De Loecker, J. (2016), Production Function Estimation with Measurement Error in Inputs. NBER Working Paper 22437.

Durlauf, S. and Quah, D. (1999), The new empirics of growth, in J. B. Taylor and M. Woodford, eds, 'Handbook of Macroeconomics', Amsterdam: North-Holland, chapter 4, pp. 235-308.

EEA (2009), Report on the Ethiopian economy: Development, prospects and challenges of the energy sector, Vol. 7, Ethiopian Economic Association, Addis Ababa, Ethiopia.

EIU (2009a), 'Ethiopia economy: Ethiopia experiences severe electricity shortages', EIU ViewsWire. The Economist Intelligence Unit. 
EIU (2009b), Ethiopia: EIU Country Report. Economist Intelligence Unit. The Economist Group. London, United Kingdom.

Engida, E., Tsehaye, E. and Tamiru, S. (2011), Does Electricity Supply Strategy Matter? Shortage and Investment. Ethiopian Development Research Institute, WP006.

FDRE (2012), Scaling-Up Renewable Energy Program: Ethiopia's Investment Plan. Ministry of Water and Energy, Federal Democratic Republic of Ethiopia.

Fisher-Vanden, K., Mansur, E. and Wang, Q. (2015), 'Electricity shortages and firm productivity: Evidence from China's industrial firms', Journal of Development Economics 114(1), 172-188.

Ghandi, A., Navarro, S. and Rivers, D. (2016), On the Identification of Production Functions: How Heterogeneous is Productivity? forthcoming in Journal of Political Economy.

Grainger, C. and Zhang, F. (2017), The Impact of Electricity Shortage on Firm Productivity: Evidence from Pakistan. World Bank Policy Research Working Paper 8130.

Griliches, G. and Hausman, J. (1986), 'Errors in variables in panel data', Journal of Econometrics 31(1), 93-118.

Kim, K., Petrin, A. and Song, S. (2016), 'Estimating production functions with control functions when capital is measured with error', Journal of Econometrics 190(2), 267-279.

Levinshohn, J. and Petrin, A. (2003), 'Estimating Production Functions Using Inputs to Control for Unobservables', Review of Economic Studies 70(2), 143-205.

Liu, D., Nordman, D. and Meeker, W. (2016), 'The Number of MCMC Draws Needed to Compute Bayesian Credible Bounds', The American Statistician 70(3), 275-284.

Mensah, J. (2018), Jobs! Electricity Shortages and Unemployment in Africa. World Bank Policy Research Working Paper 8415.

Olley, G. and Pakes, A. (1996), 'The Dynamics of Productivity in the Telecommunications Equipment Industry', Econometrica 64(6), 1263-1297. 
Powell, D. (2016), Quantile Treatment Effects in the Presence of Covariates. Working Paper, RAND Corporation.

Powell, D., Smith, T. and Baker, M. (2016), QREGPD: Stata module to perform Quantile Regression for Panel Data. Statistical Software Components. Boston College.

Reinikka, R. and Svensson, J. (2002), 'Coping with Poor Public Capital', Journal of Development Economics 69(1), 51-69.

Rovigatti, G. and Mollisi, V. (2016), PRODEST: Stata module for production function estimation based on the control function approach. Statistical Software Components. Boston College.

Shiferaw, A., Söderbom, M., Siba, E. and Alemu, G. (2015), 'Road Infrastructure and Enterprise Dynamics in Ethiopia', The Journal of Development Studies 51(11), 1541-1558.

Siba, E. and Gebreeyesus, M. (2017), 'Learning to export and learning from exporting: The case of Ethiopian manufacturing', Journal of African Economies 26(1), 1-23.

Söderbom, M. (2012), 'Firm Size and Structural Change: A Case Study of Ethiopia', Journal of African Economies 21(1), ii126-ii151.

Steinbuks, J. and Foster, S. (2010), 'When do Firms Generate? Evidence on in-house Electricity Supply in Africa', Energy Economics 32(3), 505-514.

World Bank (2015), Enterprise Surveys. The World Bank Group.

Zuberi, J. (2012), Estimating the Cost of Power Outages for Large Scale Manufacturing Firms. Working Paper, University of California at Berkley. 


\section{Appendices}

Table A.1: Unreliability of utility services to manufacturing firms

\begin{tabular}{lcc}
\hline & $\begin{array}{c}\mathrm{SSA} \dagger \\
(2010-2017)\end{array}$ & $\begin{array}{c}\text { Ethiopia } \\
(2015)\end{array}$ \\
\hline Firms experiencing electrical outages (\%) & 78.7 & 80.0 \\
Number of electrical outages in a typical month & 8.50 & 8.20 \\
Average duration of a typical outage (Hours) & 5.80 & 5.80 \\
Average losses due to electrical outages (\% annual sales) $\dagger \dagger$ & 8.30 & 6.90 \\
Domestic shipping product loss (\% total shipping) & 2.00 & 1.20 \\
Percent of firms experiencing water insufficiencies & 1.80 & 2.70 \\
\hline
\end{tabular}

$\dagger$ SSA average for latest available survey data between 2010-2017.

††Simple average across firms.

Source: Enterprise Surveys. World Bank Group.

\section{A Unbalanced panel results}

Table A.2: Electricity cost as a share of total industrial cost

\begin{tabular}{lccccc}
\hline & 2005 & 2006 & 2007 & 2008 & 2009 \\
\hline Food \& Beverage & 0.12 & 0.06 & 0.08 & 0.06 & 0.05 \\
Textile & 0.12 & 0.11 & 0.11 & 0.12 & 0.12 \\
Apparel & 0.02 & 0.02 & 0.16 & 0.18 & 0.18 \\
Leather Tanning \& footwear & 0.02 & 0.03 & 0.03 & 0.03 & 0.04 \\
Wood Products & 0.24 & 0.23 & 0.18 & 0.09 & 0.17 \\
Paper \& Paper Products & 0.05 & 0.06 & 0.05 & 0.05 & 0.06 \\
Chemicals & 0.04 & 0.04 & 0.03 & 0.03 & 0.03 \\
Rubber \& Plastics & 0.09 & 0.06 & 0.06 & 0.04 & 0.06 \\
Glass \& Non-metallic Minerals & 0.46 & 0.58 & 0.61 & 0.57 & 0.62 \\
Basic Iron, Steel, \& Casting & 0.02 & 0.01 & 0.01 & 0.09 & 0.09 \\
Metal Products & 0.04 & 0.04 & 0.04 & 0.04 & 0.03 \\
Machinery \& appliances & 0.01 & 0.01 & 0.01 & 0.01 & 0.02 \\
Motor vehicles \& accessories & 0.03 & 0.03 & 0.01 & 0.02 & 0.03 \\
Furniture & 0.02 & 0.02 & 0.02 & 0.03 & 0.02 \\
\hline Total & 0.11 & 0.10 & 0.11 & 0.10 & 0.12 \\
\hline
\end{tabular}

Table A.3: Correlation between $S^{\sigma}$ and possible reasons for lower power consumption

\begin{tabular}{lcccccc}
\hline Shortage & Electricity & Raw material & Machine parts & Customers & Working capital & Machine breakage \\
\hline Electricity & 1 & & & & & \\
Raw material & 0.01 & 1 & & & & \\
Machine parts & -0.03 & -0.12 & 1 & & & \\
Customers & 0.00 & -0.27 & -0.07 & 1 & 1 & 1 \\
Working capital & 0.00 & -0.32 & -0.09 & -0.20 & -0.12 & \\
Machine breakage & -0.02 & -0.16 & -0.04 & -0.10 & & \\
\hline
\end{tabular}


Table A.4: Estimated productivity losses from Table 4

\begin{tabular}{|c|c|c|c|c|c|c|c|c|c|c|}
\hline & \multicolumn{5}{|c|}{ FE marginal effects: $\mathrm{Col}(4)$} & \multicolumn{5}{|c|}{ IV Marginal effects: Col (8) } \\
\hline & Contrast & $\sigma_{\epsilon}$ & $\chi^{2}$ & $p_{v a l}$ & $\begin{array}{l}\text { Productivity } \\
\text { Loss }\end{array}$ & Contrast & $\sigma_{\epsilon}$ & $\chi^{2}$ & $p_{\text {val }}$ & $\begin{array}{l}\text { Productivity } \\
\text { Loss }\end{array}$ \\
\hline Disruption & & & & & & & & & & \\
\hline $\begin{array}{l}(1 \text { vs } 0) 2 \\
(1 \text { vs } 0) 3\end{array}$ & $\begin{array}{l}-0.36 \\
-0.25\end{array}$ & $\begin{array}{l}0.12 \\
0.08\end{array}$ & $\begin{array}{c}8.38 \\
10.87\end{array}$ & $\begin{array}{l}0.00 \\
0.00\end{array}$ & $\begin{array}{l}-0.30 \\
-0.22\end{array}$ & $\begin{array}{l}-0.45 \\
-0.34\end{array}$ & $\begin{array}{l}0.23 \\
0.15\end{array}$ & $\begin{array}{l}10.27 \\
13.73\end{array}$ & $\begin{array}{l}0.00 \\
0.00\end{array}$ & $\begin{array}{l}-0.52 \\
-0.42\end{array}$ \\
\hline$(1$ vs 0$) 4$ & -0.17 & 0.04 & 15.95 & 0.00 & -0.16 & -0.25 & 0.08 & 20.37 & 0.00 & -0.32 \\
\hline$(1$ vs 0$) 5$ & -0.11 & 0.02 & 21.82 & 0.00 & -0.11 & -0.19 & 0.05 & 28.80 & 0.00 & -0.23 \\
\hline$(1$ vs 0$) 6$ & -0.08 & 0.02 & 15.42 & 0.00 & -0.07 & -0.15 & 0.04 & 23.98 & 0.00 & -0.16 \\
\hline (1 vs 0$) 7$ & -0.07 & 0.02 & 11.69 & 0.00 & -0.06 & -0.14 & 0.03 & 16.13 & 0.00 & -0.13 \\
\hline$(1$ vs 0$) 8$ & -0.08 & 0.02 & 12.87 & 0.00 & -0.07 & -0.15 & 0.04 & 11.14 & 0.00 & -0.12 \\
\hline$(1$ vs 0$) 9$ & -0.11 & 0.04 & 8.59 & 0.00 & -0.11 & -0.18 & 0.07 & 5.45 & 0.02 & -0.15 \\
\hline ( 1 vs 0$) 10$ & -0.17 & 0.07 & 5.79 & 0.02 & -0.16 & -0.24 & 0.13 & 3.39 & 0.07 & -0.21 \\
\hline$(1$ vs 0$) 11$ & -0.25 & 0.12 & 4.67 & 0.03 & -0.22 & -0.32 & 0.21 & 2.74 & 0.10 & -0.29 \\
\hline Joint & & & 37.12 & 0.00 & & & & 47.18 & 0.00 & \\
\hline
\end{tabular}

Note: Productivity lost due to power disruptions at each power use intensity $\tilde{e}$

Figure A.1: Productivity loss from electricity disruptions

(Table 4, IV model: Col 8)
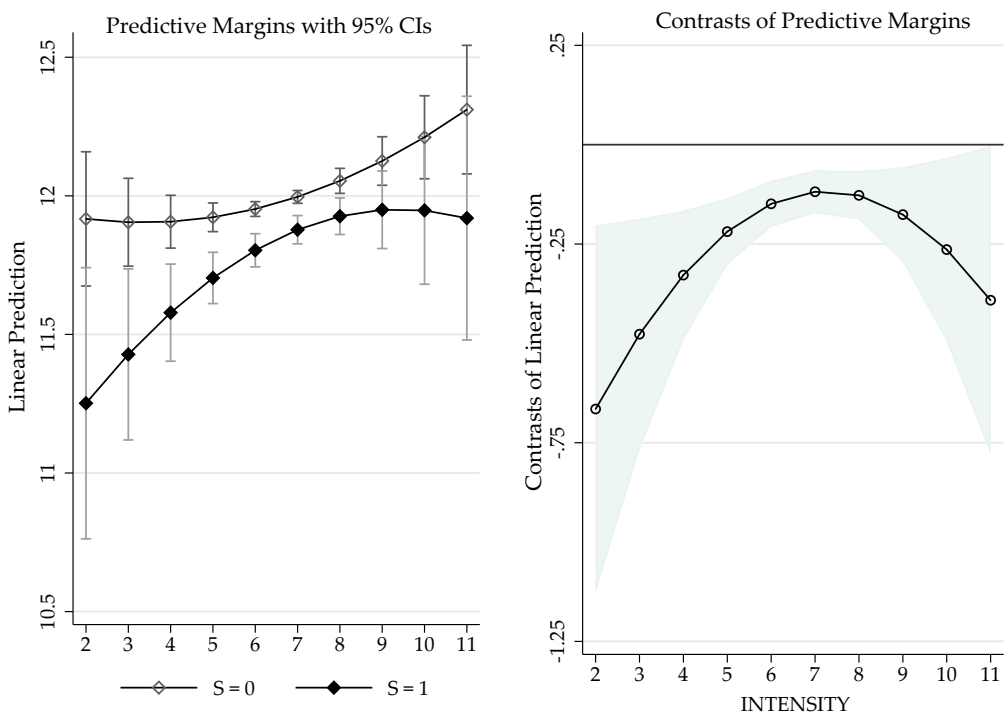

Note: INTENSITY=ẽ 
Table A.5: Fixed Effects and IV Estimation (with $S^{\sigma}$ )

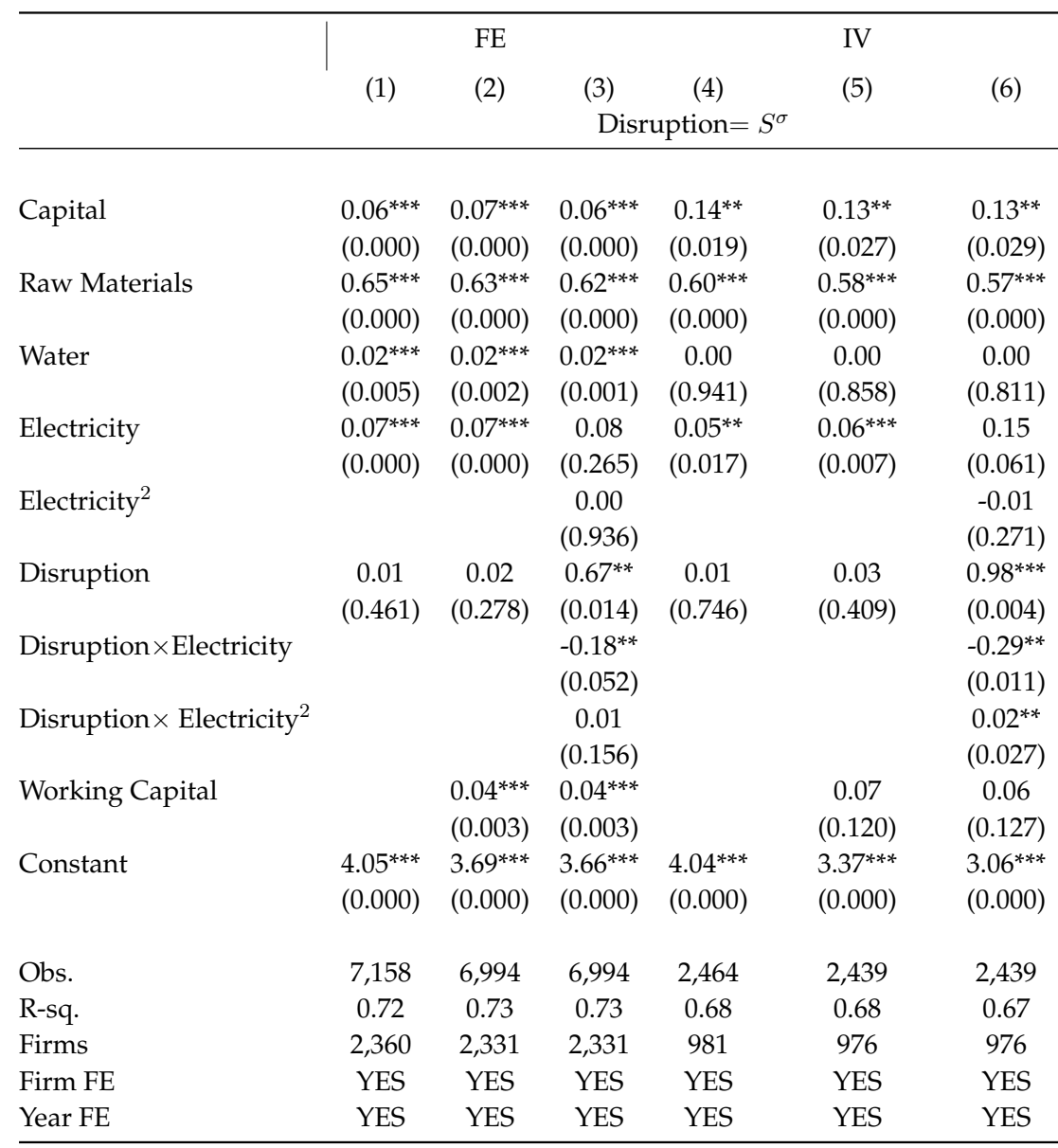

Note: Robust s.e in parenthesis. All continuous variables in log-labor units.

Lagged investment per-labor is used as an instrument for capital

Table A.6: Estimated productivity losses from Table A.5

\begin{tabular}{|c|c|c|c|c|c|c|c|c|c|c|}
\hline & \multicolumn{5}{|c|}{ FE marginal effects: Col (3) } & \multicolumn{5}{|c|}{ IV Marginal effects: Col (6) } \\
\hline & Contrast & $\sigma_{\epsilon}$ & $\chi^{2}$ & $p_{v a l}$ & $\begin{array}{l}\text { Productivity } \\
\text { Loss }\end{array}$ & Contrast & $\sigma_{\epsilon}$ & $\chi^{2}$ & $p_{v a l}$ & $\begin{array}{l}\text { Productivity } \\
\text { Loss }\end{array}$ \\
\hline Disruption & & & & & & & & & & \\
\hline $\begin{array}{l}(1 \mathrm{vs} 0) 2 \\
(1 \mathrm{vs} 0)\end{array}$ & 0.05 & 0.12 & 0.16 & 0.69 & 0.05 & 0.17 & 0.16 & 1.1 & 0.3 & $\begin{array}{r}0.18 \\
-0.02\end{array}$ \\
\hline (1 vs 0$) 3$ & -0.07 & 0.07 & 0.88 & 0.35 & -0.07 & -0.02 & 0.10 & 0.1 & 0.8 & -0.02 \\
\hline$(1$ vs 0$) 4$ & -0.17 & 0.04 & 17.24 & 0.00 & -0.16 & -0.17 & 0.07 & 6.8 & 0.0 & -0.16 \\
\hline (1 vs 0$) 5$ & -0.25 & 0.03 & 96.27 & 0.00 & -0.22 & -0.28 & 0.06 & 26.2 & 0.0 & -0.25 \\
\hline$(1$ vs 0$) 6$ & -0.32 & 0.02 & 203.92 & 0.00 & -0.27 & -0.35 & 0.05 & 48.2 & 0.0 & -0.29 \\
\hline ( 1 vs 0$) 7$ & -0.36 & 0.02 & 239.19 & 0.00 & -0.30 & -0.38 & 0.05 & 68.1 & 0.0 & -0.31 \\
\hline$(1$ vs 0$) 8$ & -0.39 & 0.04 & 95.56 & 0.00 & -0.32 & -0.36 & 0.06 & 42.1 & 0.0 & -0.30 \\
\hline (1 vs 0 ) 9 & -0.39 & 0.08 & 27.39 & 0.00 & -0.32 & -0.30 & 0.10 & 10.0 & 0.0 & -0.26 \\
\hline (1 vs 0 ) 10 & -0.38 & 0.13 & 8.94 & 0.00 & -0.32 & -0.21 & 0.16 & 1.6 & 0.2 & -0.19 \\
\hline (1 vs 0 ) 11 & -0.35 & 0.20 & 3.21 & 0.07 & -0.30 & -0.07 & 0.25 & 0.1 & 0.8 & -0.07 \\
\hline Joint & & & 283.31 & 0.00 & & & & 68.6 & 0.0 & \\
\hline
\end{tabular}

Note: Productivity lost due to power disruptions at each power use intensity $\tilde{e}$ 
Table A.7: Aggregate production functions

\begin{tabular}{lcccc}
\hline & LP & ACF & LP & ACF \\
$y$ & $(1)$ & $(2)$ & $(3)$ & $(4)$ \\
\hline & & & & \\
$l$ & $0.29^{* * *}$ & $0.67^{* * *}$ & $0.37^{* * *}$ & $0.35^{* * *}$ \\
& $(0.01)$ & $(0.02)$ & $(0.07)$ & $(0.02)$ \\
$k$ & $0.16^{* * *}$ & $0.30^{* * *}$ & $0.07^{* * *}$ & $0.10^{* * *}$ \\
& $(0.02)$ & $(0.01)$ & $(0.02)$ & $(0.02)$ \\
& $0.17^{* * *}$ & $0.22^{* * *}$ & & \\
& $(0.02)$ & $(0.02)$ & & \\
$m$ & & & $0.60^{* * *}$ & $0.64^{* * *}$ \\
& & & $(0.01)$ & $(0.01)$ \\
& & & & \\
Obs & 8,372 & 8,372 & 8,372 & 8,372 \\
Firms & 2,684 & 2,684 & 2,684 & 2,684 \\
Proxy & Raw Mat. & Raw Mat. & Electricity & Electricity \\
\hline
\end{tabular}

Note: LP = $\overline{\text { Levinsohn-Petrin estimator; } \mathrm{ACF}=\text { Ackerberg-Caves-Fraser }}$ correction

Table A.8: Industry level production functions (LP)

\begin{tabular}{llllll}
\hline & CGP & CAF & FAB & MMA & PPP \\
$y$ & $(1)$ & $(2)$ & $(3)$ & $(4)$ & $(5)$ \\
\hline \multirow{7}{*}{$l$} & $0.21^{* * *}$ & $0.24^{* * *}$ & $0.34^{* * *}$ & $0.27^{* * *}$ & $0.34^{* * *}$ \\
& $(0.03)$ & $(0.02)$ & $(0.03)$ & $(0.02)$ & $(0.05)$ \\
$k$ & $0.10^{* * *}$ & $0.10^{* *}$ & $0.14^{* * *}$ & $0.24^{* * *}$ & $0.17^{* * *}$ \\
& $(0.04)$ & $(0.04)$ & $(0.03)$ & $(0.03)$ & $(0.06)$ \\
$e$ & $0.18^{* * *}$ & $0.15^{* * *}$ & $0.16^{* * *}$ & $0.20^{* * *}$ & $0.19^{* * * *}$ \\
& $(0.04)$ & $(0.04)$ & $(0.03)$ & $(0.04)$ & $(0.05)$ \\
Obs & 1,757 & 1,069 & 2,386 & 2,308 & 843 \\
Firms & 619 & 273 & 728 & 861 & 201 \\
Proxy & Raw Mat. & Raw Mat. & Raw Mat. & Raw Mat. & Raw Mat. \\
Notes: CGP-Chemicals, Glass and Plastics; CAF-Cloth and Footwear; & FAB-Food and Beverages; MMA-Machinery, Motors \& Accessories; \\
\multicolumn{5}{c}{ PPP-Pulp, paper and printing products. }
\end{tabular}

Table A.9: Industry level production functions (ACF)

\begin{tabular}{llllll}
\hline & CGP & CFA & FAB & MMA & PPP \\
$y$ & $(1)$ & $(2)$ & $(3)$ & $(4)$ & $(5)$ \\
\hline & & & & & \\
$l$ & $0.63^{* * *}$ & $0.57^{* * *}$ & $0.69^{* * *}$ & $0.75^{* * *}$ & $0.84^{* * *}$ \\
$k$ & $(0.06)$ & $(0.01)$ & $(0.08)$ & $(0.01)$ & $(0.01)$ \\
& $0.43^{* * *}$ & $0.30^{* * *}$ & $0.30^{* * *}$ & $0.27^{* * *}$ & $0.29^{* * *}$ \\
& $(0.07)$ & $(0.03)$ & $(0.03)$ & $(0.03)$ & $(0.02)$ \\
& $0.28^{* * *}$ & $0.18^{* * *}$ & $0.26^{* * *}$ & $0.27^{* * *}$ & $0.14^{* * *}$ \\
& $(0.04)$ & $(0.04)$ & $(0.04)$ & $(0.04)$ & $(0.03)$ \\
Obs & 1,757 & 1,069 & 2,386 & 2,308 & 843 \\
Firms & 619 & 273 & 728 & 861 & 201 \\
Proxy & Raw Mat. & Raw Mat. & Raw Mat. & Raw Mat. & Raw Mat. \\
\hline
\end{tabular}


Table A.10: Industry level production functions (LP)

\begin{tabular}{llllll}
\hline & $\begin{array}{l}\text { CGP } \\
y\end{array}$ & $\begin{array}{l}\text { CFA } \\
(1)\end{array}$ & $\begin{array}{l}\text { FAB } \\
(3)\end{array}$ & $\begin{array}{l}\text { MMA } \\
(4)\end{array}$ & $\begin{array}{l}\text { PPP } \\
(5)\end{array}$ \\
\hline \multirow{l}{*}{$l$} & & & & & \\
& 0.10 & $0.27^{* * *}$ & $0.27^{* * *}$ & $0.30^{* * *}$ & $0.44^{* * *}$ \\
$k$ & $(0.13)$ & $(0.05)$ & $(0.09)$ & $(0.04)$ & $(0.08)$ \\
& $0.05^{*}$ & $0.08^{* * *}$ & $0.07^{* *}$ & $0.08^{* * *}$ & $0.06^{* *}$ \\
& $(0.03)$ & $(0.03)$ & $(0.03)$ & $(0.03)$ & $(0.03)$ \\
& $0.55^{* * *}$ & $0.65^{* * *}$ & $0.65^{* * *}$ & $0.58^{* * *}$ & $0.60^{* * *}$ \\
& $(0.02)$ & $(0.02)$ & $(0.02)$ & $(0.01)$ & $(0.03)$ \\
Obs & 1,757 & 1,069 & 2,386 & 2,308 & 843 \\
Firms & 619 & 273 & 728 & 861 & 201 \\
Proxy & Elec. & Elec. & Elec. & Elec. & Elec. \\
\hline
\end{tabular}

Table A.11: Industry level production functions (ACF)

\begin{tabular}{llllll}
\hline & $\begin{array}{l}\text { CGP } \\
y\end{array}$ & $\begin{array}{l}\text { CFA } \\
(1)\end{array}$ & $\begin{array}{l}\text { FAB } \\
(3)\end{array}$ & $\begin{array}{l}\text { MMA } \\
(4)\end{array}$ & $\begin{array}{l}\text { PPP } \\
(5)\end{array}$ \\
\hline & & & & & \\
$l$ & $0.38^{* * *}$ & $0.26^{* * *}$ & $0.40^{* * *}$ & $0.33^{* * *}$ & $0.45^{* * *}$ \\
& $(0.04)$ & $(0.04)$ & $(0.03)$ & $(0.02)$ & $(0.02)$ \\
$k$ & $0.09^{* *}$ & $0.08^{* * *}$ & $0.08^{* * *}$ & $0.13^{* * *}$ & 0.04 \\
& $(0.04)$ & $(0.02)$ & $(0.02)$ & $(0.02)$ & $(0.03)$ \\
$m$ & $0.60^{* * *}$ & $0.68^{* * *}$ & $0.68^{* * *}$ & $0.58^{* * *}$ & $0.62^{* * *}$ \\
& $(0.02)$ & $(0.01)$ & $(0.01)$ & $(0.02)$ & $(0.02)$ \\
& & & & & \\
Obs & 1,757 & 1,069 & 2,386 & 2,308 & 843 \\
Firms & 619 & 273 & 728 & 861 & 201 \\
Proxy & Elec. & Elec. & Elec. & Elec. & Elec. \\
\hline
\end{tabular}

Figure A.2: Within-industry productivity loss due to power disruptions
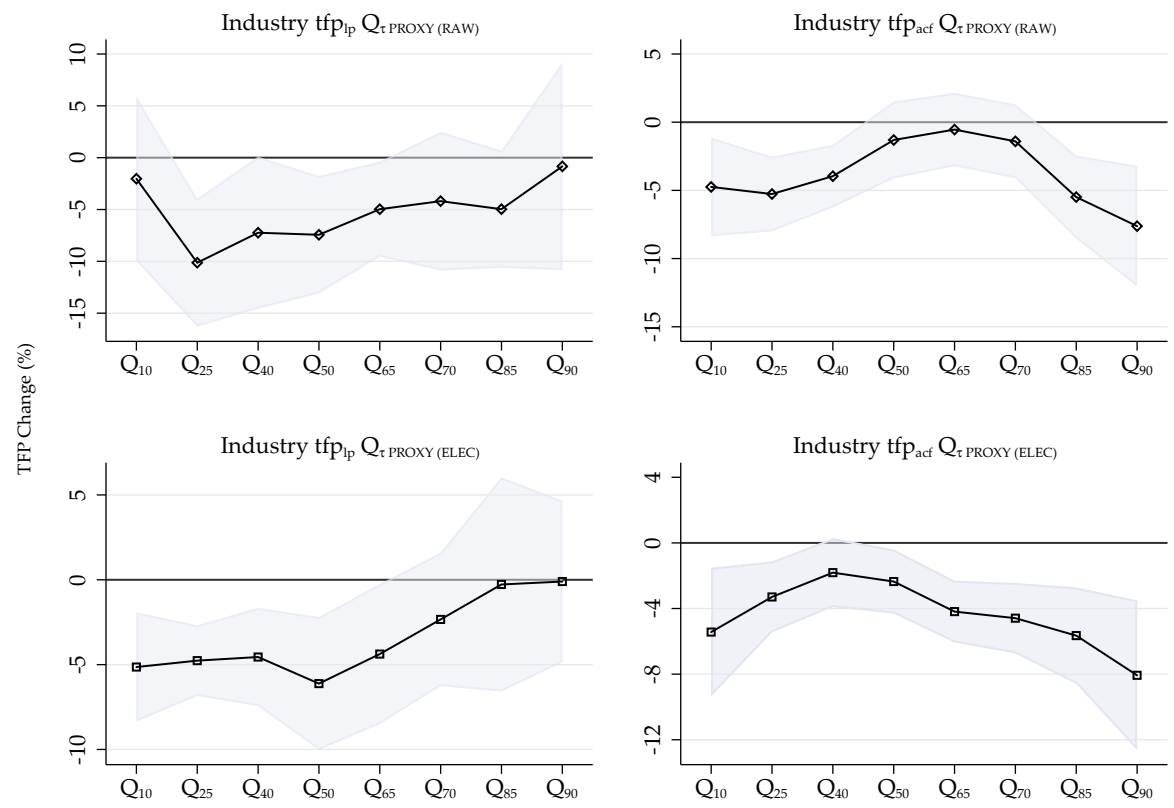

Note: Power disruption dummy $S$ 
Table A.12: Poisson Models

\begin{tabular}{|c|c|c|c|c|c|c|c|c|c|c|c|c|}
\hline \multirow[b]{2}{*}{$I$} & \multicolumn{6}{|c|}{ Random Effects Models } & \multicolumn{6}{|c|}{ Conditional Fixed Effects Models } \\
\hline & (1) & $(2)$ & (3) & $(4)$ & (5) & (6) & (7) & $(8)$ & (9) & $(10)$ & $(11)$ & (12) \\
\hline Disruption & $\begin{array}{l}0.38^{* * *} \\
(0.04)\end{array}$ & $\begin{array}{l}0.35^{* * *} \\
(0.09)\end{array}$ & $\begin{array}{l}0.42^{* * *} \\
(0.10)\end{array}$ & $\begin{array}{l}0.39^{* * *} \\
(0.08)\end{array}$ & $\begin{array}{l}0.39^{* * *} \\
(0.08)\end{array}$ & $\begin{array}{l}0.39^{* * *} \\
(0.08)\end{array}$ & $\begin{array}{l}0.37^{* * * *} \\
(0.04)\end{array}$ & $\begin{array}{l}0.35^{* * *} \\
(0.10)\end{array}$ & $\begin{array}{l}0.40^{* * *} \\
(0.11)\end{array}$ & $\begin{array}{l}0.37^{* * *} \\
(0.10)\end{array}$ & $\begin{array}{l}0.37^{* * *} \\
(0.09)\end{array}$ & $\begin{array}{l}0.38^{* * *} \\
(0.09)\end{array}$ \\
\hline$D_{t-1}^{F}$ & & $\begin{array}{l}0.17^{* * *} \\
(0.04)\end{array}$ & $\begin{array}{l}0.16^{*} \\
(0.08)\end{array}$ & $\begin{array}{l}0.14^{* * *} \\
(0.05)\end{array}$ & $\begin{array}{l}0.14^{* * *} \\
(0.05)\end{array}$ & $\begin{array}{l}0.14^{* * *} \\
(0.05)\end{array}$ & & $\begin{array}{l}0.13^{* *} \\
(0.05)\end{array}$ & $\begin{array}{l}0.08 \\
(0.07)\end{array}$ & $\begin{array}{l}0.11^{* *} \\
(0.05)\end{array}$ & $\begin{array}{l}0.11^{* *} \\
(0.05)\end{array}$ & $\begin{array}{l}0.11^{* *} \\
(0.05)\end{array}$ \\
\hline $\ln T F P_{t-1}^{L P 1}$ & & & $\begin{array}{l}-0.09 \\
(0.08)\end{array}$ & & & & & & $\begin{array}{l}-0.13 \\
(0.08)\end{array}$ & & & \\
\hline $\ln T F P_{t-1}^{A C F 1}$ & & & & $\begin{array}{l}0.003 \\
(0.05)\end{array}$ & & & & & & $\begin{array}{l}0.03 \\
(0.06)\end{array}$ & & \\
\hline $\ln T F P_{t-1}^{L P 2}$ & & & & & $\begin{array}{l}0.09 \\
(0.06)\end{array}$ & & & & & & $\begin{array}{l}0.05 \\
(0.08)\end{array}$ & \\
\hline $\ln T F P_{t-1}^{A C F 2}$ & & & & & & $\begin{array}{l}0.024 \\
(0.05)\end{array}$ & & & & & & $\begin{array}{l}0.05 \\
(0.05)\end{array}$ \\
\hline Constant & $\begin{array}{l}-0.52^{* * *} \\
(0.03)\end{array}$ & $\begin{array}{l}-1.35^{* * *} \\
(0.09)\end{array}$ & $\begin{array}{l}-1.95^{* * *} \\
(0.22)\end{array}$ & $\begin{array}{l}-1.65^{* * *} \\
(0.11)\end{array}$ & $\begin{array}{l}-1.84^{* * *} \\
(0.14)\end{array}$ & $\begin{array}{l}-1.69^{* * *} \\
(0.13)\end{array}$ & & & & & & \\
\hline Obs. & 11,094 & 6,431 & 4,856 & 6,040 & 6,040 & 6,044 & 6,418 & 3,353 & 2,151 & 3,071 & 3,071 & 3,075 \\
\hline Firms & 3,280 & 1,927 & 1,508 & 1,789 & 1,789 & 1,790 & 1,319 & 778 & 494 & 689 & 689 & 690 \\
\hline Log Lik & -19331 & -9550 & -6295 & -8650 & -8645 & -8654 & -9825 & -4633 & -3122 & -4280 & -4280 & -4280 \\
\hline
\end{tabular}


Table A.13: Alternative to count models-Pooled OLS

\begin{tabular}{|c|c|c|c|c|c|}
\hline$A$ & (1) & (2) & (3) & (4) & (5) \\
\hline Disruption & $\begin{array}{l}-0.46^{* * *} \\
(0.09)\end{array}$ & $\begin{array}{l}-0.40^{* * *} \\
(0.13)\end{array}$ & $\begin{array}{l}-0.57^{* * *} \\
(0.08)\end{array}$ & $\begin{array}{l}-0.56^{* * *} \\
(0.08)\end{array}$ & $\begin{array}{l}-0.57^{* * *} \\
(0.08)\end{array}$ \\
\hline$\Delta D^{F}$ & $\begin{array}{l}-0.31^{* * *} \\
(0.07)\end{array}$ & $\begin{array}{l}-0.36^{* * *} \\
(0.09)\end{array}$ & $\begin{array}{l}-0.32^{* * *} \\
(0.07)\end{array}$ & $\begin{array}{l}-0.31^{* * *} \\
(0.07)\end{array}$ & $\begin{array}{l}-0.33^{* * *} \\
(0.07)\end{array}$ \\
\hline$S \times \Delta D^{F}$ & $\begin{array}{l}-0.40^{* *} \\
(0.18)\end{array}$ & $\begin{array}{l}-0.27 \\
(0.30)\end{array}$ & $\begin{array}{l}-0.32^{*} \\
(0.18)\end{array}$ & $\begin{array}{l}-0.31^{*} \\
(0.18)\end{array}$ & $\begin{array}{l}-0.32^{*} \\
(0.18)\end{array}$ \\
\hline$\Delta y_{l}$ & $\begin{array}{l}0.47^{* * *} \\
(0.06)\end{array}$ & & & & \\
\hline$\Delta \ln T F P_{m}^{L P}$ & & $\begin{array}{l}0.38^{* * *} \\
(0.08)\end{array}$ & & & \\
\hline$\Delta \ln T F P_{m}^{A C F}$ & & & $\begin{array}{l}0.24^{* * *} \\
(0.09)\end{array}$ & & \\
\hline$\Delta \ln T F P_{e}^{L P}$ & & & & $\begin{array}{l}0.34^{* * *} \\
(0.10)\end{array}$ & \\
\hline$\Delta \ln T F P_{e}^{A C F}$ & & & & & $\begin{array}{l}0.17^{*} \\
(0.09)\end{array}$ \\
\hline Constant & $\begin{array}{l}0.16^{* * *} \\
(0.03)\end{array}$ & $\begin{array}{l}0.14^{* * *} \\
(0.03)\end{array}$ & $\begin{array}{l}0.08^{* * *} \\
(0.03)\end{array}$ & $\begin{array}{l}0.09^{* * *} \\
(0.03)\end{array}$ & $\begin{array}{l}0.08^{* * * *} \\
(0.03)\end{array}$ \\
\hline Obs. & 5,532 & 5,532 & 5,253 & 5,253 & 5,257 \\
\hline R-sq. & 0.05 & 0.04 & 0.03 & 0.03 & 0.03 \\
\hline Firms & 1801 & 1698 & 1698 & 1698 & 1698 \\
\hline
\end{tabular}

Note: Disruption $=S$. Clustered s.e in parenthesis.

$\Delta D^{F}=$ change in underutilized capacity;

$\Delta y_{l}=$ first differenced output per labor

Table A.14: Panel quantile regressions (Using ACF)

\begin{tabular}{|c|c|c|c|c|}
\hline & \multicolumn{2}{|c|}{ Aggregate } & \multicolumn{2}{|c|}{ Within-Industry } \\
\hline & $(1)$ & (2) & (3) & (4) \\
\hline & $\ln T F P_{A}$ & $\ln T F P_{A}$ & $\ln T F P_{I}$ & $\ln T F P_{I}$ \\
\hline \multirow[t]{2}{*}{ Disruption } & $0.18^{*}$ & $-0.05^{* * *}$ & $-0.04^{* * *}$ & $-0.04^{* * *}$ \\
\hline & $(0.02)$ & $(0.01)$ & $(0.01)$ & $(0.01)$ \\
\hline \multirow[t]{2}{*}{ Age $\times 100$} & $-1.01^{* *}$ & -1.00 & $-1.00^{* *}$ & $-1.00^{*}$ \\
\hline & $(0.00)$ & $(0.00)$ & $(0.00)$ & $(0.00)$ \\
\hline \multirow[t]{2}{*}{ Working Capital } & $0.36^{* *}$ & $0.05^{* *}$ & $0.03^{* *}$ & 0.01 \\
\hline & $(0.02)$ & $(0.01)$ & $(0.01)$ & $(0.01)$ \\
\hline Obs & 8,184 & 9,943 & 9,935 & 9,943 \\
\hline Firms & 2,649 & 2,960 & 2,958 & 2,960 \\
\hline Proxy & Raw Mat. & Electricity & Raw Mat. & Electricity \\
\hline
\end{tabular}


Figure A.3: Within-industry productivity loss due to power disruptions
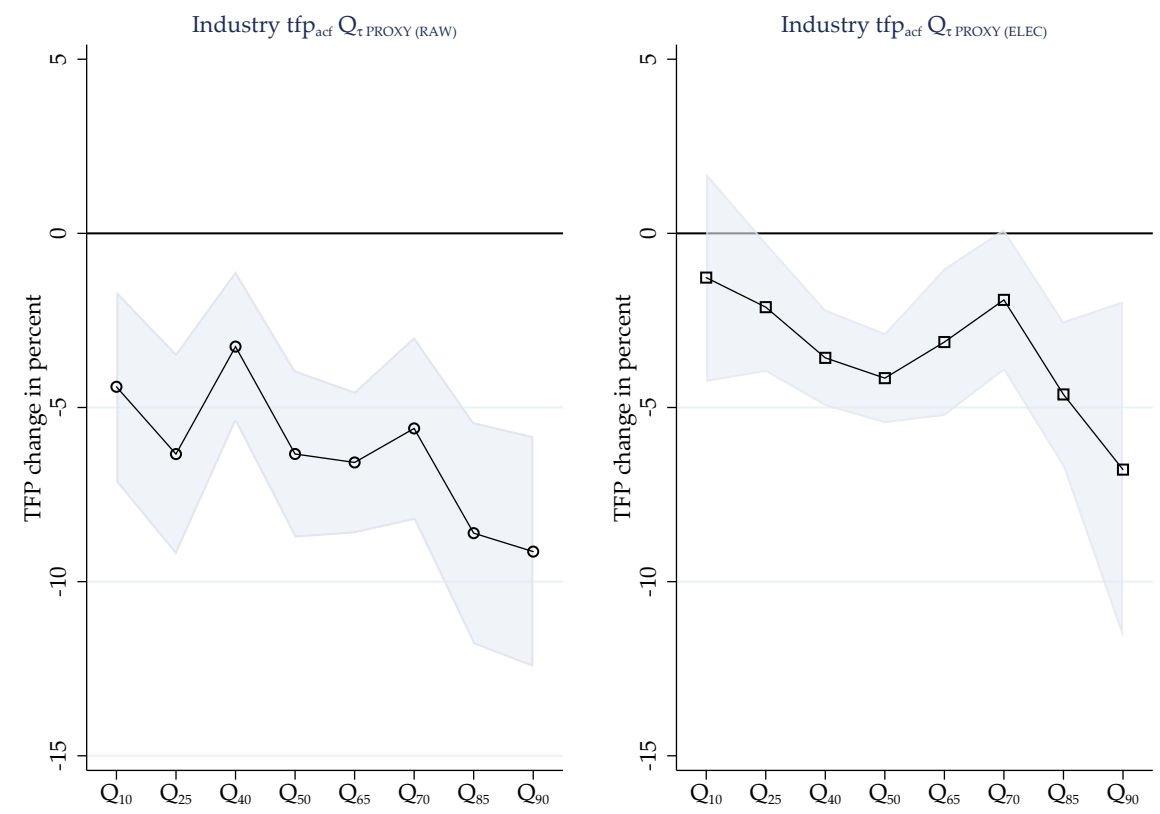

Note: Alternative power disruption dummy $S^{\sigma}$ 


\section{B Balanced panel results}

Table A.15: Fixed Effects and IV Estimation (balanced panel)

\begin{tabular}{|c|c|c|c|c|c|c|c|c|}
\hline & \multicolumn{4}{|c|}{ FE } & \multicolumn{4}{|c|}{ IV } \\
\hline & (1) & (2) & (3) & (4) & (5) & (6) & (7) & (8) \\
\hline & \multicolumn{8}{|c|}{ Disruption $=S$} \\
\hline Capital & $0.05^{* *}$ & $0.05^{* *}$ & $0.05^{* *}$ & $0.05^{* *}$ & 0.06 & 0.06 & 0.07 & 0.06 \\
\hline \multirow[t]{2}{*}{ Raw Mat. } & $0.62^{* * * *}$ & $0.62^{* * *}$ & $0.60^{* * * *}$ & $0.60^{* * *}$ & $0.59^{* * * *}$ & $0.59^{* * *}$ & $0.57^{* * *}$ & $0.57^{* * *}$ \\
\hline & $(0.033)$ & $(0.033)$ & $(0.036)$ & $(0.037)$ & $(0.048)$ & $(0.049)$ & $(0.044)$ & $(0.045)$ \\
\hline \multirow[t]{2}{*}{ Water } & $0.02^{*}$ & $0.02^{*}$ & $0.02^{* *}$ & $0.02^{* *}$ & 0.01 & 0.01 & 0.01 & 0.01 \\
\hline & $(0.009)$ & $(0.009)$ & $(0.009)$ & $(0.009)$ & $(0.010)$ & $(0.010)$ & $(0.010)$ & $(0.010)$ \\
\hline \multirow[t]{2}{*}{ Electricity } & $0.07^{* * *}$ & $0.07^{* * *}$ & $0.07^{* * *}$ & -0.10 & $0.06^{* *}$ & $0.05^{* *}$ & $0.06^{* *}$ & 0.01 \\
\hline & $(0.020)$ & $(0.019)$ & $(0.020)$ & $(0.104)$ & $(0.027)$ & $(0.028)$ & $(0.028)$ & $(0.114)$ \\
\hline Electricity $^{2}$ & & & & $\begin{array}{c}0.01 \\
(0.009)\end{array}$ & & & & $\begin{array}{c}0.00 \\
(0.008)\end{array}$ \\
\hline \multirow[t]{2}{*}{ Disruption } & & -0.03 & -0.04 & $-1.20^{* * *}$ & & -0.03 & -0.04 & $-1.51^{* * *}$ \\
\hline & & $(0.029)$ & $(0.030)$ & $(0.431)$ & & $(0.038)$ & $(0.038)$ & $(0.559)$ \\
\hline \multirow[t]{2}{*}{ Disruption $\times$ Electricity } & & & & $0.39^{* * *}$ & & & & $0.48^{* *}$ \\
\hline & & & & $(0.141)$ & & & & $(0.186)$ \\
\hline \multirow[t]{2}{*}{ Disruption $\times$ Electricity $^{2}$} & & & & $-0.03^{* * *}$ & & & & $-0.04^{* *}$ \\
\hline & & & & $(0.011)$ & & & & $(0.015)$ \\
\hline \multirow[t]{2}{*}{ Working Cap. } & & & 0.03 & 0.04 & & & 0.03 & 0.03 \\
\hline & & & $(0.026)$ & $(0.027)$ & & & $(0.070)$ & $(0.070)$ \\
\hline \multirow[t]{2}{*}{ Constant } & $4.58^{* * *}$ & $4.58^{* * *}$ & $4.33^{* * * *}$ & $4.81^{* * *}$ & $5.06^{* * *}$ & $5.00^{* * *}$ & $4.65^{* * * *}$ & $4.80^{* * *}$ \\
\hline & $(0.354)$ & $(0.354)$ & $(0.501)$ & $(0.553)$ & $(1.110)$ & $(1.124)$ & (1.549) & (1.708) \\
\hline Obs & 1,607 & 1,607 & 1,567 & 1,567 & 904 & 904 & 895 & 895 \\
\hline R-sq. & 0.82 & 0.82 & 0.83 & 0.83 & 0.81 & 0.81 & 0.82 & 0.82 \\
\hline Firms & 212 & 212 & 212 & 212 & 191 & 191 & 191 & 191 \\
\hline Firm FE & YES & YES & YES & YES & YES & YES & YES & YES \\
\hline Year FE & YES & YES & YES & YES & YES & YES & YES & YES \\
\hline U-test (p-val) & - & - & - & 0.78 & - & - & - & 0.33 \\
\hline Balanced & YES & YES & YES & YES & YES & YES & YES & YES \\
\hline
\end{tabular}

Table A.16: Estimated productivity losses from Table A.15

\begin{tabular}{|c|c|c|c|c|c|c|c|c|c|c|}
\hline & \multicolumn{5}{|c|}{ FE marginal effects: $\mathrm{Col}(4)$} & \multicolumn{5}{|c|}{ IV Marginal effects: Col (8) } \\
\hline & Contrast & $\sigma_{\epsilon}$ & $\chi^{2}$ & $p_{v a l}$ & $\begin{array}{l}\text { Productivity } \\
\text { Loss }\end{array}$ & Contrast & $\sigma_{\epsilon}$ & $\chi^{2}$ & $p_{v a l}$ & $\begin{array}{c}\text { Productivity } \\
\text { Loss }\end{array}$ \\
\hline \multicolumn{11}{|c|}{ Disruption at $\tilde{e}$} \\
\hline$(1$ vs 0$) 2$ & -0.59 & 0.20 & 8.89 & 0.00 & -0.45 & -0.76 & 0.24 & 10.08 & 0.00 & -0.53 \\
\hline$(1$ vs 0$) 3$ & -0.36 & 0.12 & 9.14 & 0.00 & -0.30 & -0.47 & 0.14 & 11.70 & 0.00 & -0.37 \\
\hline$(1$ vs 0$) 4$ & -0.19 & 0.06 & 8.27 & 0.00 & -0.17 & -0.25 & 0.07 & 11.44 & 0.00 & -0.22 \\
\hline (1 vs 0$) 5$ & -0.07 & 0.04 & 3.37 & 0.07 & -0.07 & -0.10 & 0.06 & 3.39 & 0.07 & -0.10 \\
\hline (1 vs 0$) 6$ & -0.02 & 0.04 & 0.44 & 0.51 & -0.02 & -0.03 & 0.06 & 0.35 & 0.56 & -0.03 \\
\hline$(1$ vs 0$) 7$ & -0.03 & 0.03 & 1.16 & 0.28 & -0.03 & -0.04 & 0.05 & 0.58 & 0.45 & -0.04 \\
\hline (1 vs 0$) 8$ & -0.11 & 0.04 & 6.62 & 0.01 & -0.10 & -0.11 & 0.05 & 4.98 & 0.03 & -0.10 \\
\hline (1 vs 0$) 9$ & -0.24 & 0.09 & 7.80 & 0.01 & -0.21 & -0.26 & 0.11 & 5.96 & 0.01 & -0.23 \\
\hline (1 vs 0$) 10$ & -0.43 & 0.16 & 7.54 & 0.01 & -0.35 & -0.49 & 0.21 & 5.57 & 0.02 & -0.39 \\
\hline ( 1 vs 0$) 11$ & -0.69 & 0.25 & 7.36 & 0.01 & -0.50 & -0.78 & 0.34 & 5.39 & 0.02 & -0.54 \\
\hline Joint & & & 14.64 & 0.00 & & & & 22.68 & 0.00 & \\
\hline
\end{tabular}

Note: Productivity lost due to power disruptions measured at each power use intensity $\tilde{e}$ 
Figure A.4: Productivity loss from electricity disruptions
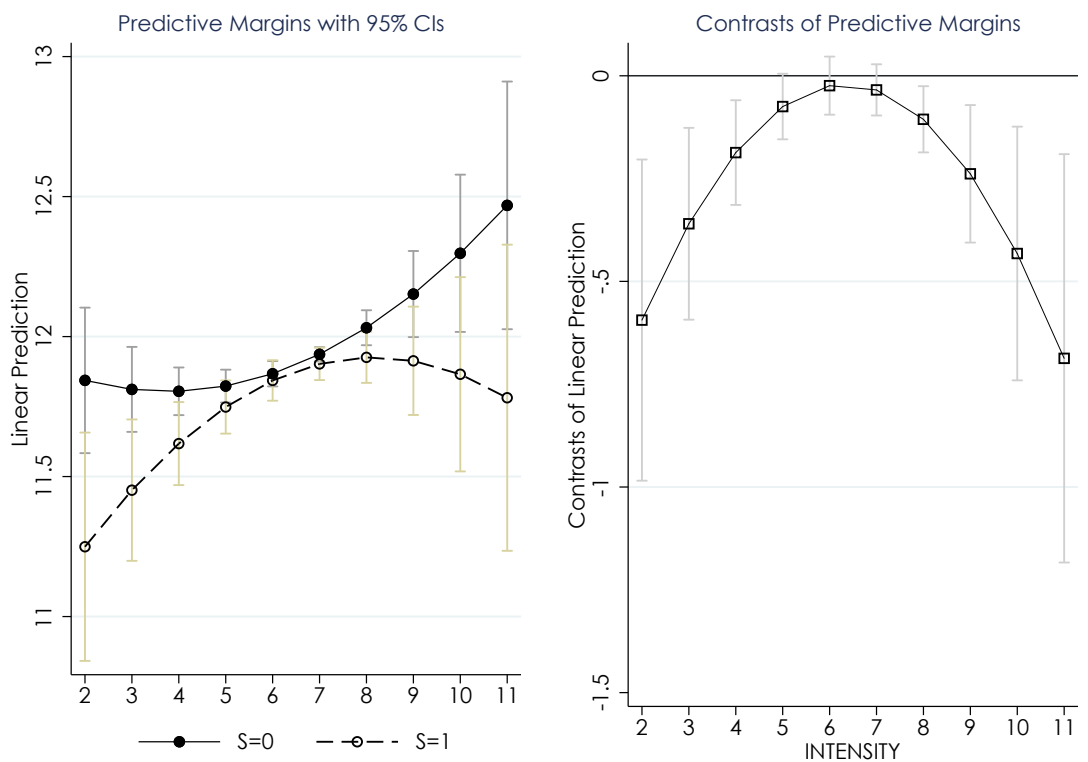

Note: Table A.15, FE model: Col 4. The left panel plots a firm's predicted log labor productivity with and without power disruptions at different power use intensities (x-axis INTENSITY=ẽ). The right panel plots the productivity differences with and without power disruptions at each intensity level $\ln \left(\frac{Y}{L} \mid S=1\right)-\ln \left(\frac{Y}{L} \mid S=0\right)$.

Table A.17: Fixed Effects and IV estimation (balanced panel)

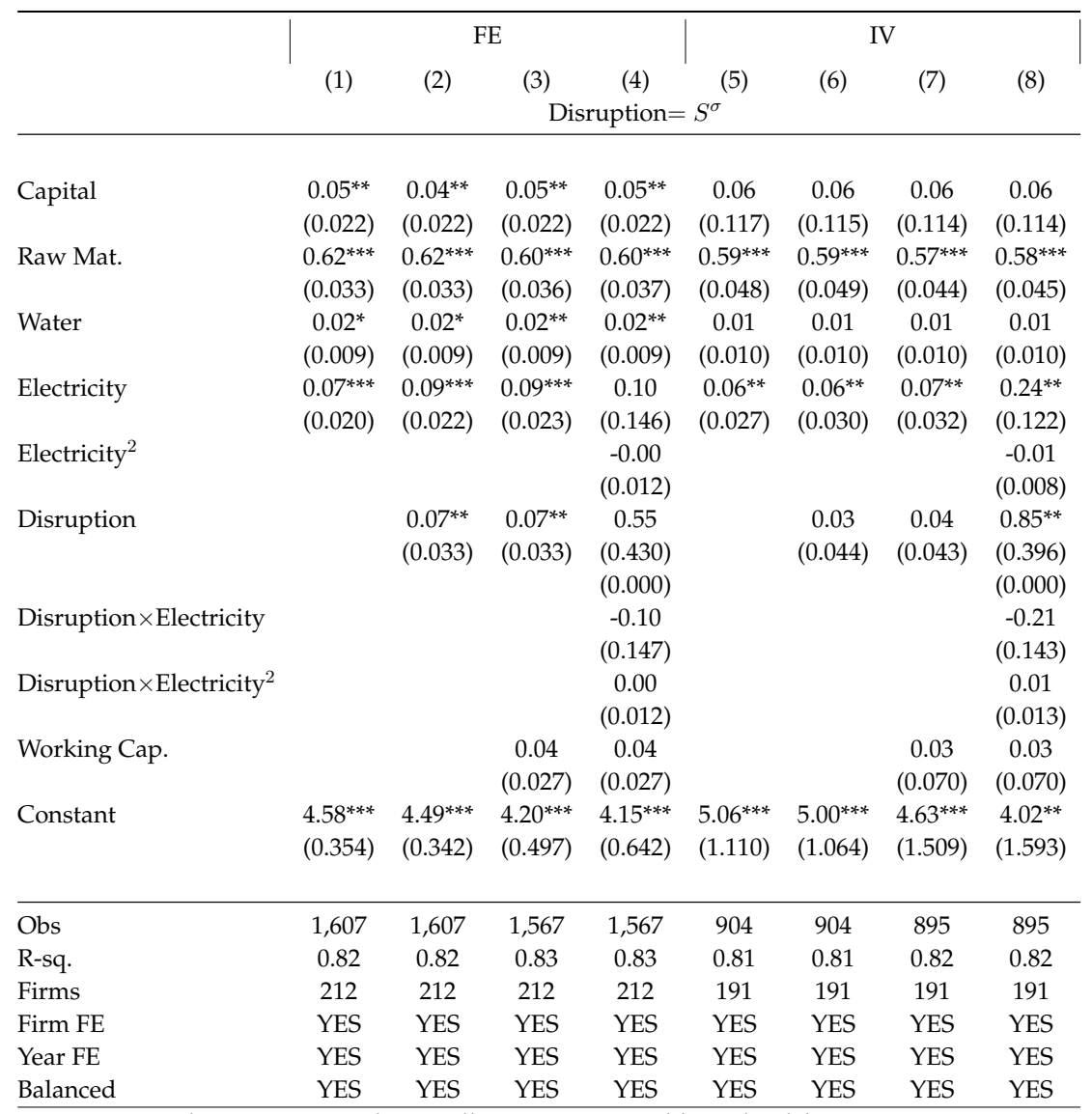

Note: Robust s.e in parenthesis. All continuous variables in log-labor units.

Lagged investment per-labor is used as an instrument for capital

CInternational Monetary Fund. Not for Redistribution 
Table A.18: Estimated productivity losses from Table A.17

\begin{tabular}{|c|c|c|c|c|c|c|c|c|c|c|}
\hline & \multicolumn{5}{|c|}{ FE marginal effects: Col (4) } & \multicolumn{5}{|c|}{ IV Marginal effects: Col (8) } \\
\hline & Contrast & $\sigma_{\epsilon}$ & $\chi^{2}$ & $p_{\text {val }}$ & $\begin{array}{c}\text { Productivity } \\
\text { Loss }\end{array}$ & Contrast & $\sigma_{\epsilon}$ & $\chi^{2}$ & $p_{\text {val }}$ & $\begin{array}{c}\text { Productivity } \\
\text { Loss }\end{array}$ \\
\hline Disruption at $\tilde{e}$ & & & & & & & & & & \\
\hline (1 vs 0$) 2$ & 0.09 & 0.19 & 0.22 & 0.64 & 0.09 & 0.28 & 0.17 & 2.79 & 0.09 & 0.33 \\
\hline (1 vs 0$) 3$ & 0.00 & 0.11 & 0.00 & 0.98 & 0.00 & 0.13 & 0.10 & 1.78 & 0.18 & 0.14 \\
\hline (1 vs 0$) 4$ & -0.08 & 0.06 & 1.39 & 0.24 & -0.07 & 0.01 & 0.06 & 0.02 & 0.89 & 0.01 \\
\hline (1 vs 0$) 5$ & -0.15 & 0.05 & 10.42 & 0.00 & -0.14 & -0.09 & 0.05 & 2.72 & 0.10 & -0.09 \\
\hline (1 vs 0$) 6$ & -0.21 & 0.04 & 25.19 & 0.00 & -0.19 & -0.16 & 0.05 & 10.05 & 0.00 & -0.15 \\
\hline (1 vs 0$) 7$ & -0.27 & 0.05 & 34.83 & 0.00 & -0.24 & -0.21 & 0.05 & 15.47 & 0.00 & -0.19 \\
\hline (1 vs 0$) 8$ & -0.32 & 0.07 & 18.51 & 0.00 & -0.28 & -0.23 & 0.09 & 7.49 & 0.01 & -0.21 \\
\hline (1 vs 0$) 9$ & -0.37 & 0.14 & 7.21 & 0.01 & -0.31 & -0.23 & 0.15 & 2.28 & 0.13 & -0.21 \\
\hline (1 vs 0$) 10$ & -0.40 & 0.23 & 3.18 & 0.07 & -0.33 & -0.20 & 0.25 & 0.66 & 0.42 & -0.18 \\
\hline$(1$ vs 0$) 11$ & -0.43 & 0.34 & 1.61 & 0.20 & -0.35 & -0.15 & 0.37 & 0.16 & 0.69 & -0.14 \\
\hline Joint & & & 38.52 & 0.00 & & & & 15.79 & 0.00 & \\
\hline
\end{tabular}

Note: Productivity lost due to power disruptions measured at each power use intensity $\tilde{e}$

Figure A.5: Productivity loss from electricity disruptions
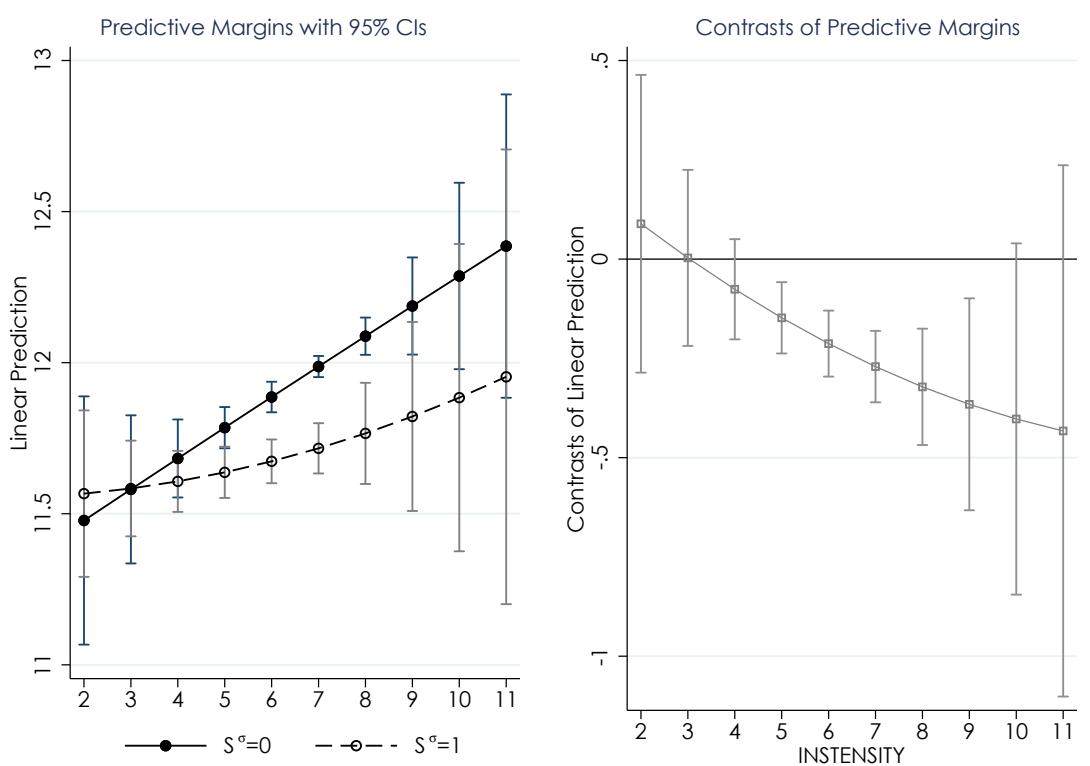

Note: Table A.17, FE model: Col 4. The left panel plots a firm's predicted log labor productivity with and without power disruptions at different power use intensities ( $x$-axis INTENSITY=ẽ). The right panel plots the productivity differences with and without power disruptions at each intensity level $\ln \left(\frac{Y}{L} \mid S^{\sigma}=1\right)-\ln \left(\frac{Y}{L} \mid S^{\sigma}=0\right)$. 